Annelies Crabbe $^{\mathrm{a}}$, Caroline Vandeputte ${ }^{\mathrm{b}}$, Tom Dresselaers ${ }^{\mathrm{c}}$, Angel Ayuso Sacido ${ }^{\mathrm{d}}$, Jose Manuel Garcia Verdugo $^{\mathrm{d}}$, Jeroen Eyckmans ${ }^{\mathrm{e}}$, Frank P. Luyten ${ }^{\mathrm{e}}$, Koen Van Laere ${ }^{\mathrm{b}}$, Catherine M Verfaillie ${ }^{\mathrm{a}}$, Uwe Himmelreich $^{c}$ a: Stem Cell Institute, K.U.Leuven, Leuven, 3000, Belgium b: Division of Nuclear Medicine, K.U.Leuven, Leuven, 3000, Belgium c: Biomedical NMR Unit/ MOSAIC, K.U.Leuven, Leuven, 3000, Belgium Spain

13 Annelies Crabbe and Caroline Vandeputte contributed equally to this work

14 The authors claim no conflict of interest.

15 Running head: Effect of contrast agent on stem cell

16 Corresponding author:

17 Annelies Crabbe

18 Stamcelinstituut Leuven

19 O\&N1 - Herestraat 49, bus 804, 3000 Leuven, Belgium

20 Telephone: 003216330292 Fax: 003216330294

$21 \quad$ Annelies.crabbe@med.kuleuven.be 
23

The ultimate therapy for ischemic stroke is restoration of blood supply in the ischemic region and regeneration of lost neural cells. This might be achieved by transplanting cells that differentiate into vascular or neuronal cell types, or secrete trophic factors that enhance self-renewal, recruitment, longterm survival and functional integration of endogenous stem/progenitor cells. Experimental stroke models have been developed to determine potential beneficial effect of stem/progenitor cell based therapies. To follow the fate of grafted cells in vivo, a number of non-invasive imaging approaches have been developed. Magnetic Resonance Imaging (MRI) is a high resolution, clinically relevant method allowing in vivo monitoring of cells labeled with contrast agents. In this study, labeling efficiency of 3 different stem cell populations (mouse Embryonic Stem Cells, rat Multipotent Adult Progenitor Cells and mouse Mesenchymal Stem Cells) with three different (ultra) small superparamagnetic iron oxide (U)SPIOs particles (Resovist ${ }^{\circledR}$, Endorem $^{\circledR}$, Sinerem ${ }^{\circledR}$ ) was compared. Labeling efficiency with Resovist ${ }^{\circledR}$ and Endorem ${ }^{\circledR}$ differed significantly between the different stem cells. Labeling with (U)SPIOs in the range that allows detection of cells by in vivo MRI, did not affect differentiation of stem cells when labeled with concentrations of particles needed for MRI-based visualization. Finally, we demonstrated that labeled rMAPC could be detected in vivo and that labeling did not interfere with their migration. We conclude that successful use of (U)SPIOs for MRI based visualization will require assessment of the optimal (U)SPIO for each individual (stem) cell population to ensure the most sensitive detection without associated toxicity.

\footnotetext{
Keywords: Stem cells, MRI, stroke, iron oxide particles, (U)SPIO, animal models
} 
Neurological disorders such as stroke result in irreversible brain tissue damage for which there is no available curative treatment yet. An increasing number of investigators are exploring cell replacement approaches to treat neurological disorders, by grafting stem/progenitor cells in animal models $(6,18,27,29,40,41,43,47,53)$. Clinically suitable methods are needed to follow the fate of the grafted cells in vivo to understand in a temporal manner mechanisms of stem cell survival and functional integration (22).

Due to its noninvasive nature, high contrast in soft tissue and high spatial resolution, Magnetic Resonance Imaging (MRI) is one of the most powerful clinical diagnostic tools available today. For biomedical applications like cell tracking, grafted cells must be visualized against the background of host tissue. Therefore, cells have to be labeled with contrast agents (for review see $(7,16,17,30)$. One can use positive contrast agents used in T1-weighted MRI such as lanthanoide-chelates (12) or Mncontaining compounds $(51,52)$. Alternatively, negative contrast agents, such as superparamagnetic iron oxide (SPIO) $(4,7,24,31,37,54)$, ultra small superparamagnetic iron oxide (USPIO) particles $(4,18,24,31)$ or micron-sized iron oxide particles $(39,46)$ are highly sensitive and have a dominant effect on the $\mathrm{T} 2 / \mathrm{T} 2 *$ relaxation times, causing negative contrast enhancement in the regions of interest. Multiple attributes of these particles determine the labeling efficacy of the agents, including the size of the iron oxide particles, the charge and the nature of the coating (for review see $(17,30)$ ). These physicochemical characteristics not only affect the efficacy of the particles for MRI, but also their stability, biodistribution, metabolism and their clearance from the vascular system (11). The internalization of (U)SPIOs can be enhanced through pretreatment of these particles with transfection agents. The latter are highly charged macromolecules that have been used to transfect DNA into cells via electrostatic interaction resulting in endosome formation $(2,4,18,24)$.

Although labeling of cells has shown to be successful for many applications, very few studies have evaluated its effects on cell function $(1,23,42,44)$. The goal of this study was to determine whether different stem cell populations being considered for the therapy of neurological disorders, including 
72 murine mesenchymal stem cells (mMSC), murine embryonic stem cells (mESC) and rat multipotent 73 adult progenitor cells (rMAPC) could be labeled with similar efficiency using different nanoparticles. 74 The stability of the labeling after prolonged culture in vitro was also evaluated. In addition, potential 75 toxic effects of the labeling on the three stem cell populations were examined. Finally, the possibility 76 of in vivo detection of labeled rMAPC was assessed, as well as the effect of the labeling on cell 77 distribution when grafted in the setting of photothrombotic lesions.

78 
mMSC from C57Bl/6 mice were obtained from Dr. D Prockop, Tulane University, USA, where they were isolated and shown to differentiate into adipocytes and osteoblasts (33). Isolation and characteristics of rMAPC from Fisher rats has been described elsewhere (5). mESC from 129 mice (R1 line) were received from the Vesalius Research Institute (K.U. Leuven, Belgium). All cell lines were maintained as described previously (48). Prior to use in our studies, mESC were replated feederfree on $0.1 \%$ gelatin (Chemicon, Billerica, USA) coated plates.

Cell labeling

The following magnetic resonance iron-based contrast agents were used: Resovist ${ }^{\circledR}$ (particle diameter $60 \mathrm{~nm}$ ), (Shering, Munchen, Germany), Sinerem ${ }^{\circledR}$ (particle diameter 20-40nm) and Endorem ${ }^{\circledR}$ (particle diameter 80-150nm) (both Guerbet, Roissy, France). Cell labeling was performed by co-culture of the cells with (U)SPIOs with and without transfection agents (23kDa or $388 \mathrm{kDa}$ Poly-L-lysine) for 4 to $24 \mathrm{hrs}$. The concentration of (U)SPIOs was tested in a range of 20 to $500 \mu \mathrm{g}$ total iron per $\mathrm{ml}$ of culture medium. Final concentrations used were Resovist ${ }^{\circledR}: 50 \mu \mathrm{g} / \mathrm{ml}$; Endorem ${ }^{\circledR}: 348 \mu \mathrm{g} / \mathrm{ml} ;$ Sinerem ${ }^{\circledR}$ :

$96500 \mu \mathrm{g} / \mathrm{ml}$.

Iron quantification

Cell pellets of labeled and unlabeled cells were collected $24 \mathrm{hrs}$, $48 \mathrm{hrs}$ and $72 \mathrm{hrs}$ after labeling and mineralized 'au bain marie' prior to Induced Coupled Plasma-Mass Spectroscopy (ICp-MS) (Perkin

100 Elmer, Massachussetts, USA). Values per tube were calculated as follows: total iron content per pellet

$101=\mu \mathrm{g}$ total iron per liter $\mathrm{x}$ (mass mineralized $\mathrm{BM} /$ density mineralized $\mathrm{BM}$ ) $\mathrm{x}$ dilution (according to 102 Guerbet protocol). 
105 Cells were fixed with 10\% NBF (60\% PBS and 40\% formaldehyde (Sigma, St Louis, USA)) for 15 106 min, washed and incubated for $15 \mathrm{~min}$ with PBS (Sigma) $+0.1 \%$ Triton (Sigma). Next, cells were 107 rinsed and stained with mouse anti-dextran-FITC (1:1000, Stem Cell Technologies, Vancouver, 108 Canada) overnight. The next day, cells were rinsed and staining was detected using fluorescent 109 microscope (AxioImager, Zeiss, Gottingen, Germany).

\section{Cell proliferation}

111 Labeled cells were cultured in their specific expansion medium under standard conditions (48). Cells

112 were counted each day using a nucleocounter. Population doubling time (PDT) was calculated as 113 follows: $\mathrm{T} \times \operatorname{Ln} 2 / \operatorname{Ln}(\mathrm{A} / \mathrm{A} 0)$, with $\mathrm{T}=$ time between two cell counts, $\mathrm{A}=$ the number of cells at end, $114 \mathrm{~A} 0=$ the initial number of cells. We followed the PDT of the labeled cell populations for 7 days.

\section{Cell differentiation assays}

116 Differentiation of mMSC to the osteogenic and adipogenic lineage was performed according to 117 standardized methods $(13,14,35)$. Differentiation of rMAPC to the endothelial, neuroectodermal and 118 hepatic lineage was performed as described in (48).

119 In vitro osteogenic assays: Unlabeled and (U)SPIO labeled mMSC were seeded at $10^{4}$ cells/ $/ \mathrm{cm}^{2}$ in $24-$

120 well plates. After 2 days in culture, the medium was replaced by osteogenic medium [expansion 121 medium supplemented with $100 \mathrm{nM}$ dexamethasone, $10 \mathrm{mM}$ beta-glycerophosphate and $50 \mu \mathrm{M}$ 122 ascorbic acid 2-sulfate (Sigma)] for 3 weeks (25). The cells were lysed in $150 \mu$ PBS containing $1230.05 \%$ Triton X 100 (Sigma). Alkaline phosphatase activity was measured using a commercially 124 available kit (Kirkegaard \& Perry, Guildford, UK), according to the manufacturer's instructions. DNA 125 content was determined with the Quant-iT ${ }^{\mathrm{TM}}$ dsDNA HS Assay (Invitrogen). Parallel samples were 126 processed for RNA extraction at 6 and 14 days. After 3 weeks of treatment with osteogenic medium, 127 calcium deposits were stained with alizarin red. After taking pictures with a Nikon Coolpix 995 128 camera through an inverted microscope (Telaval 31, Zeiss), alizarin red was extracted as described 
previously and absorbance was measured at 492nm. Unlabeled bone marrow-derived cells (hBMDCs)

130 were used as positive control.

131 In vitro adipogenesis: Unlabeled and (U)SPIO labeled mMSC were seeded in 24 well plates at a cell

132 density of $10^{4}$ cells $/ \mathrm{cm}^{2}$. Cells were allowed to become confluent in expansion medium. Adipogenic 133 induction medium was then added, consisting of expansion medium supplemented with $1 \mu \mathrm{M}$ 134 dexamethasone, $0.5 \mathrm{mM}$ methyl-isobutylxanthine, $10 \mu \mathrm{g} / \mathrm{ml}$ insulin, and $100 \mathrm{mM}$ indomethacin (all 135 from Sigma). After $72 \mathrm{hrs}$, the medium was changed to adipogenic maintenance medium $(10 \mu \mathrm{g} / \mathrm{ml}$ 136 insulin in culture medium) for $24 \mathrm{hrs}$. Cells were treated 4 times with induction medium. The cells 137 were then maintained in adipogenic maintenance medium for 1 week before fixation. After 21 days 138 cells were washed twice with PBS, fixed with $0.2 \%$ glutaraldehyde (Sigma) for 5 min, washed with 139 PBS, rinsed in $60 \%$ isopropanol, and covered with oil red O solution ( $0.1 \%$ oil red O [Sigma] in $60 \%$ 140 isopropanol). After $10 \mathrm{~min}$, cultures were briefly rinsed in $60 \%$ isopropanol, washed thoroughly in 141 distilled water, and counterstained with hematoxylin.

142 Differentiation of MAPC to the endothelial, neuroectodermal and hepatic lineage was performed as 143 described in Ulloa-Montoya et al. (48).

144 Briefly, for endothelial differentiation, rMAPC were plated in fibronectin-coated wells. On day 1, 145 medium was switched to a differentiation medium (low glucose DMEM/MCDB-201 (60:40) 146 containing 10ng/ml hVEFG-A (R\&D Systems), 1X ITS, $1 \mathrm{X}$ LA-BSA, $10^{-8} \mathrm{M}$ dexamethasone, $10^{-4} \mathrm{M}$

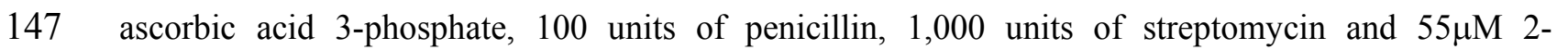
148 mercaptoethanol (Cellgro). RNA samples were collected on day 9 for analysis.

149 For hepatic differentiation, rMAPC were plated in matrigel coated wells in low glucose 150 DMEM/MCDB-201 (60:40) containing $2 \%$ FBS, $0.25 \mathrm{X}$ ITS， 0.5X LA-BSA， $0.1 \times 10^{-6} \mathrm{M}$ 151 dexamethasone, $10^{-4} \mathrm{M}$ ascorbic acid 3-phosphate, 100 units of penicillin, 1,000 units of streptomycin 152 and $55 \mu \mathrm{M}$ 2-mercaptoethanol. The following cytokines were added sequentially: $100 \mathrm{ng} / \mathrm{mL}$ Activin$153 \mathrm{~A}$ and 50ng/mL BMP4; 10ng/ml FGF2 and 25ng/mL FGF8b; and 20ng/m HGF and 10ng/ml 154 Oncostatin-M (all from R\&D systems). RNA samples were collected on day 20 for analysis. 
155 For neuroectoderm differentiation, MAPC were plated on gelatin coated T75 flasks in N2B27

156 medium (DMEM-F12:NeurobasalA medium (Invitrogen) 1:1 supplemented with N2 supplement (1x,

157 R\&D) and B27 (1x, Invitrogen), 100 units of penicillin, 1,000 units of streptomycin, 55 $\mu \mathrm{M} 2-$

158 mercaptoethanol and 200nM L-glutamine (Invitrogen). After 2 days medium was changed to NSE

159 medium (Euromed medium (Euroclone) supplemented with N2 supplement (1x, R\&D), 200nM L-

160 glutamine (Invitrogen), 100 units of penicillin, 1,000 units of streptomycin and bFGF (10ng/ml,

161 R\&D) and EGF (10ng/ml, R\&D). RNA samples were collected on day 6 for analysis.

$162 R T-q P C R$

163 Experiments were conducted as described (48). For rMAPC and mESC, total RNA from

164 undifferentiated and differentiated cells was extracted using the RNAeasy microkit (Qiagen, Valencia,

165 CA). cDNA was generated by reverse transcription using Superscript III ReverseTranscriptase

166 (Invitrogen, Carlsbad, USA). To test the expression of gene(s) of interest a real-time PCR was

167 performed as follows: 40 cycles of a two step PCR $\left(95^{\circ} \mathrm{C}\right.$ for 15 ", $60^{\circ} \mathrm{C}$ for $\left.45^{\prime \prime}\right)$ after initial

168 denaturation $\left(95^{\circ} \mathrm{C}\right.$ for $\left.10^{\prime}\right)$ with $2 \mu 1$ of cDNA solution, $2 \mathrm{X}$ SYBR Green Universal Mix PCR reaction

169 buffer (Invitrogen). Expression of target genes was normalized to Gapdh. Gene expression level

170 represented as Delta $\mathrm{CT}$ : Delta $\mathrm{CT}\left(\mathrm{CT}_{\text {gene of interest }}-\mathrm{CT}_{\mathrm{GAPDH}}\right)$. Primers used for amplification:

171 rOct 4 (f: CTGTAACCGGCGCCAGAA, r: TGCATGGGAGAGCCCAGA);

172 rSox2 (f:AACCCCAAGATGCACAACTC, r:CCGGGAAGCGTGTACTTATC);

173 rPax6 (f:GTCCATCTTTGCTTGGGAAA, r:TAGCCAGGTTGCGAAGAACT);

174 rVimentin (f: AATGCTTCTCTGGCACGTCT,r: GCTCCTGGATCTCTTCATCG);

175 rEn1 (f: CAGAGACTCAAGGCGGAGTT,r: CCTGTGGCTTTCTTGATCTTG);

$176 r v W F \quad$ (f: CCCACCGGATGGCTAGGTATT,r: GAGGCGGATCTGTTTGAGGTT);

177 rFlk1 (f: CCAAGCTCAGCACACAAAAA,r: CCAACCACTCTGGGAACTGT);

178 rPecam (f: GGACTGGCCCTGTCACGTT,r: TTGTTCATGGTGCCAAAACACT);

179 rProx1 (f: GGAGATGGCTGAGAACAAGC,r: AGACTTTGACCACCGTGTCC);

$180 \mathrm{rAfp}$ (f: ACCTGACAGGGAAGATGGTG,r: GCAGTGGTTGATACCGGAGT); 
For osteogenic and adipogenic differentiation studies, cells and cell pellets obtained in the in vitro differentiation experiments were homogenized in a cell lysis buffer from the RNA-extraction kit (Nucleospin, BD Biosciences). RNA extraction was performed according to manufacturer's recommendations. Complementary DNA (cDNA) was obtained by reverse transcription of $1 \mu \mathrm{g}$ of total RNA with Oligo $(\mathrm{dT}) 20$ as primer (RevertAid ${ }^{\mathrm{TM}}$ H Minus First Strand cDNA Synthesis Kit; Fermentas Life Sciences). To evaluate gene expression, taqman PCR was performed on Corbett 6000

193 Rotorgene system (Westburg) using the assay-on-demand probes from Applied Biosystems. (Assay 194 numbers: GAPDH: 4352339E ALP: Mm01187117_m1, iBSP: Mm00492555_m1) cDNA obtained 195 from expanded mBMCs before labeling and treatment was used as a reference sample. Gene 196 expression levels are listed as Delta CT: delta $\mathrm{CT}\left(\mathrm{CT}_{\text {gene of interest }}-\mathrm{CT}_{\mathrm{GAPDH}}\right)$.

198 Cells were fixed with $3.5 \%$ glutaraldehyde (Electron microscopy Science, Hatfield, USA) for 1hr at

$19937^{\circ} \mathrm{C}$. Cells were post-fixed with $1 \%$ osmiumtetroxide (Sigma), rinsed, dehydrated and embedded in 200 araldite (Durcupan, Sigma). Semithin sections $(1.5 \mu \mathrm{m})$ were cut with a diamond knife and stained 201 lightly with 1\% toluidine blue (Panreac, Barcelona, Spain). Semithin sections were re-embedded in an 202 araldite block and detached from the glass slide by repeated freezing (liquid nitrogen) and thawing. 203 The block with semi-thin sections was cut in ultra-thin $(0.05 \mu \mathrm{m})$ sections with a diamond knife, 204 stained with lead citrate and examined under a Tecnai spirit electron microscopy (FEI). Photographic 205 images were taken with a Morada camera (Soft Image System, Munster, Germany). For (U)SPIOs 206 particle quantifications an average of 5 ultra-thin sections corresponding to different locations were 207 analyzed for every time point and the quantification was carried out by three independent scientists. 
209 FACS staining was performed as described (48). Unlabeled and (U)SPIO labeled cells were collected 210 by trypsinization, washed with PBS (Invitrogen) containing 3\% FBS and blocked for 10 min with 5\% 211 rat serum (Jackson ImmunoResearch, West Grove, USA) and 10 $\mu 1$ anti CD16/CD32 (2.4G2) antibody 212 (BD bioscience). After washing, cells were incubated for $30 \mathrm{~min}$ at $4^{\circ} \mathrm{C}$ in $3 \% \mathrm{FBS}$ containing 213 conjugated antibodies. Cells were washed once and resuspended in PBS 3\% FBS and analyzed by 214 flow cytometry on FACSCanto (BDPharmingen, San Jose USA). Antibodies used to characterize 215 rMAPC were anti-CD44-FITC (OX-49) and antiCD31-PE (TLD-3A12). Mouse IgG2a,k (G155-178) 216 and mouse IgG1, $\mathrm{K}$ (MOPC-31C) are respectively used as isotype controls. For mMSC anti-CD44217 APC (IM7) and anti-ckit-PE (2B8) were used and rat IgG2b, (A95-1) was used as isotype control (all 218 antibodies were from BDPharmingen, San Diego, CA).

\section{Cytogenetics}

220 Evaluation of cell ploidy was performed as described (48). Demecolcine $(10 \mu \mathrm{g} / \mathrm{ml}$ in HBSS 221 Invitrogen) was added to the media until $50 \%$ of the cells were detached. Media was removed and the 222 remaining attached cells were collected following rinsing. Cells were centrifuged at 1000 RPM for 5 $223 \mathrm{~min}$, and the pellet transferred to a conical tube with PBS. $0.0075 \mathrm{M} \mathrm{KCl}$ was added, pre-warmed to $22437^{\circ} \mathrm{C}$. After $10 \mathrm{~min}$, cells were centrifuged and the pellet mixed with fixative. Cell suspensions were 225 dropped on the slide and allowed to dry. Slides were stained with 1:5 diluted Wright-Giemsa stain $226(0.4 \% \mathrm{w} / \mathrm{v}$ in $\mathrm{MeOH})$ in Gurr Buffer (Gibco). The number of chromosomes per cell was enumerated 227 for at least 40 cells under a light microscope (Zeiss).

Photothrombotic animal model and cell injections

229 Animal experiments were approved by the bioethics committee of K.U.Leuven (P06098, Leuven, 230 Belgium). Male and female NOD-SCID/gamma $\mathrm{c}^{-/-}$mice were obtained from the breeding colony in 231 the SPF facility at K.U.Leuven. Male Fisher 344 rats were purchased from Charles River, Wilmington, 232 USA. All animals were housed with access to food and water. For surgery, 3-week-old mice or 8- 
week-old rats were anesthetized intraperitoneally with ketamine (Ketamine 1000, $75 \mathrm{mg} / \mathrm{kg}$;CEVA

234 Santé Animale, Libourne, France) and medetomidin (Domitor, $1 \mathrm{mg} / \mathrm{kg}$; Orion Pharma, Espoo, 235 Finland).

236 Cortical photothrombosis was induced in 8 mice and 8 rats. A vertical incision was made between the 237 right orbit and the external auditory canal. The upper part of the temporalis muscle was cauterized so 238 that the muscle could be displaced. Photoillumination with green light (wave length, 540nm; 239 bandwith, 80nm) was achieved using a Xenon lamp (model L-4887; Hamamatsu Photonics, 240 Hamamatsu City, Japan) with heat-absorbing and green filters. The irradiation at intensity of $2410.68 \mathrm{~W} / \mathrm{cm}^{2}$ was directed with a $3 \mathrm{~mm}$ optic fiber, which was placed on the exposed skin above the 242 Midlle Cerebral Artery. Photoillumination was performed for $20 \mathrm{~min}$ after intravenous injection of the 243 photosensitizer Rose Bengal (20mg/kg, Sigma-Aldrich) in a tail vein. Control experiments were 244 performed without injection of the photosensitizer. No photothrombotic injury was detected in control 245 animals.

246 Injection of $\mathrm{GFP}^{+} \mathrm{MAPC}$ was performed in 8 control mice to establish detectability thresholds and 247 also in 8 rats 2 days after photothrombosis. The head of the animals was positioned in a stereotactic 248 head frame (Stoelting, Wood Dale, IL) for stereotactic injection into the striatum. The skull was 249 exposed by a small midline incision and a hole was drilled into the skull in the appropriate location, 250 using bregma as the reference point. Stereotactic coordinates starting from the dura were as follows: 251 Lateral $+0.20 \mathrm{~cm}$ for left injection, $-0.20 \mathrm{~cm}$ for right injection; Anterior-posterior $+0.05 \mathrm{~cm}$; depth $3 \mathrm{~mm}$ 252 to $2 \mathrm{~mm}$ (mice). Lateral $+0.28 \mathrm{~cm}$ for left injection, $-0.28 \mathrm{~cm}$ for right injection; Anterior-posterior 0.11 $253 \mathrm{~cm}$; depth 4mm (rat). Using a 30-gauge Hamilton syringe (VWR International, Haasrode, Belgium), 25410,000 or 50,000 labeled cells were injected in mice or 10,000 or $1,000,000$ cells were injected in rat 255 at a rate of $0.25 \mu 1 / \mathrm{min}$ into left or right striatum, respectively. After injection, the needle was left in 256 place for an additional $5 \mathrm{~min}$ before slowly withdrawn. Anesthesia was reversed with atipamezol 257 (Antisedan, 0.5mg/kg; Orion Pharma), administered intraperitoneally. 
260 For the assessment of the in vitro visualization of (U)SPIO labeled cells by MRI, phantoms were built 261 using culture dishes $(3.5 \mathrm{~cm}$ diameter) filled with agar (Sigma-Aldrich, $0.8 \%$ in saline). Drill holes 262 (4mm diameter of a defined depth) were filled with cell suspensions of known concentration. After 263 solidification of the cell-agar suspensions, drill holes were closed with additional agar. All MR images 264 were acquired using a Bruker Biospec 9.4 Tesla small animal MR scanner (Bruker Biospin, Ettlingen, 265 Germany; horizontal bore, $20 \mathrm{~cm})$ equipped with actively shielded gradients $\left(600 \mathrm{mT} \mathrm{m}^{-1}\right)$. A purpose266 built radio-frequency solenoid transmit-receive coil with a length of $6 \mathrm{~cm}$ and an inner diameter of $4 \mathrm{~cm}$ 267 was used for all phantom experiments. 2D multi-slice-multi-echo (MSME) experiments were acquired 268 for the calculation of $\mathrm{T}_{2}$-maps $\left(\mathrm{TR}=6,000 \mathrm{~ms}\right.$ and $10 \mathrm{TE}$ increments of $10 \mathrm{~ms}, 256^{2}$ matrix, $156 \times 156$ $269 \mu \mathrm{m}$ in plane resolution, $0.8 \mathrm{~mm}$ slice thickness). T2* maps were acquired similarly to MSME experiments using a gradient echo pulse sequence and $10 \mathrm{TE}$ increments of $4.5 \mathrm{~ms}$. Three-dimensional 271 (3D), high-resolution $T_{2}{ }^{*}$ - weighted $M R$ images were acquired using a gradient echo sequence $272\left(\right.$ FLASH, TR=200 ms, TE $=15 \mathrm{~ms}$, flip angle $30^{\circ}$ ). The field-of-view was $3.8 \times 3.8 \times 0.75 \mathrm{~cm}$. The 273 resolution was usually $74 \times 74 \times 59 \mu \mathrm{m}$.

\section{In vivo MRI experiments}

276 MR images from animals were usually acquired within $12 \mathrm{hrs}$ after photothrombosis. Subsequent 277 images were acquired within $12 \mathrm{hrs}$ after cell engraftment and were repeated for up to 10 days after 278 implantation. MR images were acquired using an actively decoupled linear polarized RF resonator as 279 transmitter (inner diameter 7cm, Bruker Biospin) with respective mouse and rat brain surface coils 280 (Bruker Biospin) as receiver. After acquisition of 2D multislice localizer images, 2D MSME 281 experiments were acquired for the calculation of $\mathrm{T}_{2}$-maps ( $\mathrm{TR}=6,000 \mathrm{~ms}$ and $10 \mathrm{TE}$ increments of $28210 \mathrm{~ms}, 256^{2}$ matrix, $156 \times 156 \mu \mathrm{m}$ in plane resolution, $0.8 \mathrm{~mm}$ slice thickness). High resolution 3D 283 FLASH images were acquired for the visualization of labeled cells thereafter resulting in an isotropic 284 spatial resolution of $100 \mu \mathrm{m}^{3}$. Other acquisition parameters were TR $=100 \mathrm{~ms}$, TE $=12 \mathrm{~ms}$, flip angle $28530^{\circ}$. Diffusion-weighted MR images (spin echo) were acquired for the first two time points after the 
photothrombotic injury for assessment of injury. Acquisition parameters were: $\mathrm{TR}=1500 \mathrm{~ms}, \mathrm{TE}=27$ $\mathrm{ms}, \mathrm{B}=1500$, in plane isotropic resolution $156 \mu \mathrm{m}^{2}, 1 \mathrm{~mm}$ slice thickness.

\section{MRI data processing}

Images were processed using Paravision 4 (Bruker Biospin) and NIH ImageJ. Relaxation rates $\left(\mathrm{r}_{2}\right)$ were determined as mean values of homogeneous sections of the cell loaded areas in the agar phantoms. Values were compared to those of unlabeled cells in the same phantom. Relative quantification was also performed using $3 \mathrm{D} \mathrm{T} 2 *$-weighted $\mathrm{MR}$ images. The relative mean signal intensity of the respective drill holes was determined relative to unlabeled cells ( $\mathrm{SI}=100 \%)$. Data were expressed as mean $\pm \mathrm{SD}$.

Immunohistochemistry

Animals were sacrificed at 1,5 or 3 weeks after injection with an intraperitoneal overdose $(300 \mu 1 / 20 \mathrm{~g})$ of pentobarbital (Nembutal; CEVA Santé Animale) and transcardially perfused with 4\% (w/v) paraformaldehyde (PFA, Sigma) in PBS. Brains were removed and postfixed overnight in 4\% PFA. Serial $50 \mu \mathrm{m}$ coronal sections were made with a microtome (Vibratome, St. Louis, MO). Hematoxylin/ eosin staining was performed for all brains to assess injury. GFP staining was performed for visualization of transplanted cells (1:30, Clonetech, CA, USA).

\section{Statistical analysis}

304 For in vitro experiments student's paired two-tailed t test was used for comparison of 2 experimental 305 groups. Changes were identified as significant if $\mathrm{p}<0.05$. When multiple groups were compared, 306 Bonferroni correction was applied. Data are shown as mean + /- standard deviation. 
311 Labeling efficiency of mMSC, rMAPC and mESC with Resovist ${ }^{\circledR}$, Sinerem ${ }^{\circledR}$ and Endorem $^{\circledR}$

312 In initial experiments, we tested the optimal time for labeling and whether addition of transfection 313 agents was needed for labeling with Resovist ${ }^{\circledR}$, Sinerem ${ }^{\circledR}$ and Endorem ${ }^{\circledR}$. Greater amounts of 314 (U)SPIOs were taken up by cells incubated for $24 \mathrm{hrs}$ with either Resovist ${ }^{\circledR}$, Sinerem $^{\circledR}$ and Endorem ${ }^{\circledR}$ 315 compared to incubation for $4 \mathrm{hrs}$ (microscopy after Prussian Blue staining). Hence all subsequent 316 studies were done by incubating cells $24 \mathrm{hrs}$. Particle clustering was observed when $23 \mathrm{kDa}$ poly-L317 lysine (PLL) instead of $388 \mathrm{kDa}$ PLL was used as transfection agent together with Resovist ${ }^{\circledR}$. Hence, 318 all further experiments were performed using 388kDa PLL. Comparison of (U)SPIOs uptake with and 319 without the transfection agent (PLL) showed that Resovist ${ }^{\circledR}$ and Sinerem ${ }^{\circledR}$ were taken up (more 320 efficiently) in the presence of PLL compared with uptake experiments without the transfection agent. 321 However, uptake of Endorem ${ }^{\circledR}$ was not affected by the presence or absence of PLL (data not shown). 322 Optimal labeling was defined as being able to detect the lowest cell density ( 15 cells/ $\mu$ l) for one of the 323 three stem cell populations by MRI of phantoms containing labeled cells. After testing various 324 (U)SPIO concentrations and incubation times, this was achieved using the following conditions: $32550 \mu \mathrm{g} / \mathrm{ml}$ Resovist ${ }^{\circledR}$ combined with $0.75 \mu \mathrm{g} / \mathrm{ml}$ Poly-L-Lysine $(388 \mathrm{kDa}), 500 \mu \mathrm{g} / \mathrm{ml}$ Sinerem ${ }^{\circledR}$ 326 combined with $0.75 \mu \mathrm{g} / \mathrm{ml}$ Poly-L-Lysine $(388 \mathrm{kDa})$, and $348 \mu \mathrm{g} / \mathrm{ml}$ Endorem $^{\circledR}$ without transfection 327 agent for $24 \mathrm{hrs}$ (data not shown).

328 The size, amount, density and localization of (U)SPIO inclusions in the cells was evaluated by 329 transmission electron microscopy (TEM). As shown in Table 1, the number of inclusions per rMAPC 330 was significantly higher for Sinerem ${ }^{\circledR}$ compared to Endorem $^{\circledR}$ and Resovist ${ }^{\circledR}$. The average size of 331 inclusions, representing clustered (U)SPIOs, was significantly higher for Resovist ${ }^{\circledR}$ and Sinerem ${ }^{\circledR}$ 332 when compared to Endorem ${ }^{\circledR}$. The density of inclusions was significantly higher for Endorem ${ }^{\circledR}$ and 333 Resovist $^{\circledR}$ compared with Sinerem ${ }^{\circledR}$. The quantity of internalized iron per cell was evaluated by ICP334 MS as shown for time points day1, day2 and day3 after labeling for 24hrs (Fig. 1ABC). When 335 different particles were compared within one cell population, higher concentrations of iron were 
detected in rMAPC and mMSC labeled with Resovist ${ }^{\circledR}$ (2.51 and $11.58 \mathrm{pg} /$ cell respectively) at day 1 , while in $\mathrm{mESC}$ the highest concentration of iron was found following labeling with Endorem ${ }^{\circledR}$

$338(4.14 \mathrm{pg} / \mathrm{cell})$ at day 1 . In general, the most iron was in average detected in mMSC, most likely due to 339 their larger size (surface area measured by TEM: mMSC $363.61+/-267.76 \mu \mathrm{m}^{2}$; rMAPC $157.81+/-$ $340 \quad 89.93 \mu \mathrm{m}^{2}$ and $\left.\mathrm{mESC} 114.54+/-61.48 \mu \mathrm{m}^{2}\right)$.

341 The quantity of iron per rMAPC decreased significantly at day3 (fold decrease of 3.9 for Resovist ${ }^{\circledR}$,

3425.3 for Endorem $^{\circledR}$ and 4.25 for Sinerem ${ }^{\circledR}$ ). In mESC there was significant decrease of iron for 343 Resovist $^{\circledR}$ by day3 (fold decrease 2.1) and for Sinerem ${ }^{\circledR}$ by day2 (fold decrease 1.4). In contrast, no 344 reduction could be observed in mMSC (see Fig. 1). The number of inclusions over time was also 345 evaluated. As expected, in all three stem cell types, the number of inclusions decreased over time (Fig 346 1DEF).

347 In vitro evaluation of cell labeling by MRI

348 Visualization of stem cells by MRI is only successful if the amount of (U)SPIOs taken up is sufficient 349 to alter contrast in MRI. To determine if sufficient particles were present in cells to be visualized by 350 MRI, we made agar phantoms containing different numbers of labeled cells to determine the minimum 351 detectable cell number. To assess the effect of dilution of intracellular (U)SPIOs due to cell 352 proliferation and its influence on cell detectability, phantoms containing cells were scanned $24 \mathrm{hrs}$, $35348 \mathrm{hrs}$ and $72 \mathrm{hrs}$ after labeling. Figure 2 shows 3D T2* weighted MRI as well as T2- and T2*-maps of 354 cell phantoms. Cell densities as low as 5 cells $/ \mu 1$ were detectable for cells labeled with Endorem ${ }^{\circledR}$ 355 (mESC, rMAPC, mMSC) or Resovist ${ }^{\circledR}$ (rMAPC, mMSC). Labeling with Sinerem ${ }^{\circledR}$ resulted in less 356 contrast resulting in a detectability limit in the order of 75 cells $/ \mu 1$. The MRI contrast strongly 357 depended on the combination of stem cell type and contrast agent. Resovist ${ }^{\circledR}$ was superior over 358 Endorem $^{\circledR}$ for rMAPC and for mMSC labeling. However, labeling of mESC was most efficient using 359 Endorem $^{\circledR}$ compared to Resovist $^{\circledR}$ (Fig. 2A). Moreover, contrast in T2*-weighted MRI was more 360 pronounced in the larger mMSC for all particles compared to mESC and rMAPC. Absolute 361 quantification of cell numbers was not possible due to large magnetic susceptibility effects of the 
labeled cells at high densities. Fitting for T2- and T2*-maps was not possible due to signal quench

363 even for the lowest echo times. Counting of erased pixel clusters in 3D T2*-weighted MR images of 364 cell suspensions of low density (as described by Kustermann et al. (24)) did not yield a correlation 365 with cell numbers due to cell clustering.

366 When cells were cultured for $48 \mathrm{hrs}$ in iron free medium prior to MRI, decreased detectability of 367 labeled cells was observed (Fig. 2B). Consistent with experiments immediately after cell labeling (Fig. 368 2A), sensitivity of MRI detection strongly depended on the combination of stem cell type and 369 (U)SPIO. In line with the results of iron uptake (Fig. 1), Endorem ${ }^{\circledR}$ was more efficient for mESC 370 labeling whereas Resovist ${ }^{\circledR}$ resulted in better detectability of rMAPC and mMSC. The lower 371 proliferation rates of mMSC compared to rMAPC and mESC resulted in less dilution of the contrast 372 agents with time and similar detectability thresholds after additional $72 \mathrm{hrs}$ incubation in iron free 373 medium (data not shown).

\section{Effect of labeling on stem cell proliferation, phenotype and genetic integrity}

375 We evaluated whether labeling of mMSC, rMAPC and mESC with either (U)SPIO affects cell 376 proliferation over a period of 7 days. Results are shown in Fig 3. Labeling of mMSC with Sinerem ${ }^{\circledR}$ 377 resulted in an increased PDT on d5, compared with unlabeled cells or cells labeled with Endorem ${ }^{\circledR}$ and 378 Resovist $^{\circledR}$. However by day 7, no significant differences were noted between mMSC labeled with any 379 of the contrast agents compared with unlabeled mMSC (Fig. 3A). Labeling with any of the contrast 380 agents did not affect mESC PDT over the 7 day period (Fig. 3B). By contrast, labeling of rMAPC with 381 either Sinerem ${ }^{\circledR}$ or Endorem ${ }^{\circledR}$ resulted in a lengthening of the PDT on d5, which was statistically 382 significant compared to cells labeled with Resovist ${ }^{\circledR}$ or unlabeled cells (Fig. 3C). The phenotype of 383 mMSC, rMAPC and mESC was validated following labeling with the different (U)SPIOs. mESC 384 represent pluripotent stem cells (21), characterized by the expression of key transcription factors that 385 maintain the pluripotent state. Among these is the Pou5f1 transcription factor, also known as Oct4 386 (32). We determined the transcript levels of Oct4 in mESC 2 days after labeling with the (U)SPIOs. In 387 Resovist $^{\circledR}$ labeled mESC, the level of Oct4 transcripts was 2.77 fold higher compared to control, 
although this was not statistically significant (Fig. 4A). We have previously shown that, similar to mESC but in contrast to mMSC, rMAPC also express Oct4, and that presence of Oct4 is associated with the significantly broader differentiation potential of rMAPC (48). Therefore, the expression of 391 Oct4 was also evaluated in rMAPC 2 days after labeling with (U)SPIOs and in unlabeled controls. As for mESC, we could not detect a statistically significant difference in Oct4 transcript levels in rMAPC labeled with any of the (U)SPIOs compared to unlabeled rMAPC (Fig. 4B).

394 We and others have shown that mMSC, used in the present study, express among others the cell 395 surface anitgen CD44 at high levels, but not c-kit $(33,47)$. rMAPC are CD44 ${ }^{\mathrm{dim}} / \mathrm{CD} 31^{+}(5,48)$. To 396 ascertain that labeling with (U)SPIOs did not affect the mMSC and rMAPC cell identity, we evaluated 397 cells 3 days after labeling with the 3 contrast agents by FACS. No obvious changes in cell surface phenotype were identified following labeling (Fig 4CD).

We also assessed whether labeling with any of the (U)SPIOs would cause increased aneuploidy of mMSC, rMAPC or mESC. It should be noted that previous published studies have shown that mMSC 401 become aneuploid very quickly after isolation, including the mMSC population used here (19). 402 Compared to unlabeled control cells, the ploidy of labeled cells was not decreased for up to five days after labeling (rMAPC: $72.17 \%+/-3.50$; mESC: $50.9 \%+/-8.82$; mMSC: $3.3 \%+/-0.01$ ).

Effect of labeling on stem cell differentiation

Previous reports suggested that labeling of stem cells, such as mMSC, with (U)SPIOs may affect their differentiation ability (23). We therefore tested the effect of (U)SPIO-labeling on the differentiation ability of mMSC and rMAPC (Fig. 5).

408 mMSC differentiate towards osteoblasts and adipocytes $(33,35,36)$. Treatment with dexamethasone, 409 beta-glycerophosphate and L-ascorbic acid, to induce osteogenic differentiation resulted in a similar 410 increase in alkaline phosphatase (Fig.5A), and calcium deposition by day 14 when labeled and 411 unlabeled mMSC were compared. Statistically significant increases in transcripts for the osteogenic markers, Alp (26) and Bsp (15), were similar in labeled and unlabeled cells on day 14 of osteogenic 
413 differentiation (Fig. 5B). Adipogenic differentiation was induced using insulin and assessed by Oil

414 Red O staining (Fig. 5C). Cells stained with Oil Red O were similar in labeled or unlabeled cells, for

415 Sinerem ${ }^{\circledR}$-labeled cells a modest decrease in staining is seen based on visual observations. Hence,

416 labeling of mMSC with Resovist ${ }^{\circledR}$, Sinerem ${ }^{\circledR}$ or Endorem $^{\circledR}$ did not affect the differentiation ability of

417 mMSC towards osteoblasts and adipocytes. As shown in Fig. 5I-N, TEM demonstrated persistent

418 presence of the different (U)SPIOs in the differentiated mMSC progeny over the whole time period of

419 the experiment.

420 In comparison with mMSC, rMAPC have significantly broader differentiation ability, and can 421 generate progeny of the three germ layers (48). To assess the effect of (U)SPIO labeling on rMAPC 422 differentiation, differentiation to hepatocyte-, endothelium- and neuroectodermal progenitor-like cells 423 was induced using methods described previously (48). Lineage differentiation was assessed by RT424 qPCR for lineage specific gene transcripts (Fig. 5DEF). Differentiation towards hepatocyte-like cells 425 was induced using a multistep protocol as described (48). For labeled or unlabeled cell populations, a 426 similar increase in transcripts for alpha-fetoprotein (Afp) (9), albumin (Alb) as well as the mature 427 hepatocyte gene Tat (8) was seen by day 21 (Fig. 5D). Differentiation to endothelium of rMAPC 428 labeled with (U)SPIOs and unlabeled controls was induced with VEGF-A. A similar induction of 429 Flk1, Prox1 and Pecam (20) was observed Fig. 5E. Differentiation of rMAPC towards 430 neuroectodermal progenitor cells was achieved using a protocol based on studies by Conti et al. (10) 431 and described in Ulloa et al. (48). A similar increased expression of transcripts for Sox2 and Pax6 (50) 432 was found in labeled and unlabeled cells (Fig. 5F).

433 Samples from differentiated rMAPC-progeny were fixed and analyzed under TEM. rMAPC-derived 434 hepatocytic and endothelial progeny continued to contain (U)SPIOs in, respectively, $20 \%$ and $100 \%$ of 435 the cells (Fig. 5GH).

\section{In vivo tracking of labeled cells in the brain}

437 As proof of principle for in vivo cell visualization, rMAPC labeled with Resovist ${ }^{\circledR}$ were 438 stereotactically engrafted into the striatum of NOD-SCID $\gamma \mathrm{c}^{-/-}$mice. 10,000 and 50,000 rMAPC 
suspended in $2 \mu \mathrm{l}$ PBS were injected in the left and right hemisphere respectively. Animals were 440 monitored repeatedly by MRI for three weeks. As shown in Fig. 6A-B, 10,000 cells could be 441 visualized in 3D T2* MR images. The contrast and the hypointense volume of the implanted cells in 442 MRI remained constant over the observation period (data not shown). Control injections with PBS or 443 unlabeled cells did not change contrast apart from injuries due to the surgical procedure (needle track). 444 Location of cells in the MRI was confirmed by histology (Fig. 6C).

445 As also confirmed by MRI, rMAPC were injected 1-3 mm from a photothrombotic lesion. Cells were 446 found along the corpus callosum towards the infarct region within 24hrs. However, no infiltration of 447 rMAPC into the lesion area was seen (Fig. 6D).

448 Experiments were repeated in eight-week-old Fisher rats with a phototrombotic injury (Fig. 7). 449 Resovist ${ }^{\circledR}$-labeled rMAPC were injected close to the lesion $24 \mathrm{hrs}$ after photothrombosis. 450 Combinations of 100,000 labeled $\left(\right.$ Resovist $^{\circledR}$ ) GFP $^{+}$rMAPC with or without 900,000 unlabeled 451 rMAPC were injected in the brain 2 to $8 \mathrm{~mm}$ from the photothrombotic injury localized in the cortex of 452 male Fisher rats $(n=8)$. Cell relocation into less dense brain tissue such as the Corpus Callosum and the 453 stroke region or along the needle tract was visualized by MRI (Fig. 7C). Localization of the cells was 454 confirmed with GFP staining and Hematoxylin-eosin staining (Fig. 7DE). Unlabeled control cells 455 showed a similar distribution pattern suggesting that labeling does not appear to affect the 456 redistribution of rMAPC in vivo (Fig. 7B and data not shown). When mMSC were implanted, no 457 redistribution of the cells along the corpus callosum was found (Fig. 7A). 
464 Non-invasive imaging plays an important role in stem cell research because it allows following an 465 individual animal over time and studying the temporal behavior of endogenous or transplanted stem 466 cells. One of the most clinically relevant imaging modality is MRI, because of its high spacial resolution in comparison with for instance PET, and the possibility to label cells without the need for genetic manipulation that is needed to introduce other markers such as fluorochromes in cells.

For many applications, contrast agents like highly sensitive (U)SPIOs are used for negative contrast enhancement $(4,7,18,31,39,46,54)$. Due to their physicochemical characteristics, label uptake and stability of the particles in cells differs between different types of (U)SPIOs $(2,4,18)$. In addition, some reports have suggested that (U)SPIO labeling may affect certain biological properties of cells $(24,28,38,45)$. However, only limited data exist on the comparison of labeling efficiency and possible toxicity of the particles on different stem/progenitor cell populations. In this study, cell labeling efficiency of three stem cell populations, mMSC, rMAPC and mESC with three (U)SPIOs (Resovist ${ }^{\circledR}$, Endorem $^{\circledR}$ and Sinerem ${ }^{\circledR}$ ) was compared, and potential adverse effects of different labeling procedures on the biology of the cells was examined.

Two of the three particles tested, Resovist ${ }^{\circledR}$ and Sinerem ${ }^{\circledR}$, are taken up better by the stem/progenitor cells when PLL $388 \mathrm{kDa}$ is added, whereas uptake of Endorem ${ }^{\circledR}$ is not further enhanced when a

480 transfection agent is added to the particle. Our study also demonstrates that different amounts of iron 481 in the culture medium are necessary for the three (U)SPIO to visualize the cells by MRI. Also, the 482 labeling efficiency with three different (U)SPIOs varies significantly when different stem cell 483 populations are compared. This was shown by a combination of techniques, including dextran staining 484 (for Endorem $^{\circledR}$ and Sinerem ${ }^{\circledR}$ ), measurement of intra-cellular iron by ICP-MS, electronmicroscopy 485 which also demonstrated that the number and distribution of iron particle inclusions within cells 486 differed for the various (U)SPIOs. These findings were also confirmed by in vitro MRI, which 487 reflected the data from ICP-MS. Comparison of electron microscopy with iron quantification (ICP488 MS) and MRI indicates that the size and density of occlusions but not the number of occlusions 
correlates with the internalized amount of iron and MRI contrast. The small size of Sinerem ${ }^{\circledR}$ results in

490 a larger number of small inclusions that are less dense and therefore contain less iron compared to 491 Endorem $^{\circledR}$ and Resovist ${ }^{\circledR}$. These results demonstrate that labeling methods will likely need to be 492 optimized for every cell type that is used. Over time, we saw a decrease of iron in the cells. This is 493 mainly due to dilution of (U)SPIOs with cell division but might also occur due to exocytosis of the 494 particles (24). The PDT of mESC and rMAPC is $12 \mathrm{hrs}$, whereas the PDT for mMSC is $48 \mathrm{hrs}$, which 495 explains the significant reduction of iron in rMAPC. However, as this is not observed in mESC, 496 further studies on exocytosis are needed to evaluate the loss of iron. In this study, two cell populations 497 were from murine origin and one from rat. Whether the species origin plays a role in the efficiency of 498 stem cell labeling is not known. Also not known is the mechanism(s) underlying the differences in 499 labeling efficiency between cell types.

The second major goal of this study was to evaluate whether (U)SPIO labeling affects the biology of 501 cells, as at least some studies suggested that labeling of mMSC affects differentiation potential 502 (24,37). No significant alterations were observed in the cell phenotype of mMSC, rMAPC and mESC 503 following labeling, whereas differentiation ability of mMSC or rMAPC remained unchanged. For rMAPC progeny committed to an endothelial and hepatocytic phenotype, the labeling persisted until final differentiation of these cells, demonstrating that the label does not significantly affect stem cell differentiation. However, neural progeny contained few remaining SPIOs, likely due to extensive

507 proliferation occurring during the generation of NSC-like cells from rMAPC. Hence, no images are 508 shown from this experiment. Similarly, labeling persisted in mMSC differentiated to the adipocyte and 509 osteocyte lineage, without influencing the differentiation process. It should be noted, however, that 510 Sinerem $^{\circledR}$ decreased proliferation of mMSC, and both Sinerem ${ }^{\circledR}$ and Endorem ${ }^{\circledR}$ affected the 511 proliferation of rMAPC, even though prolonged culture (until 7 days) resulted in restoration of the proliferation rate. Large numbers of endosomal inclusions might thus affect the proliferation capacity

513 of mMSC and rMAPC. This may particularly be true for rMAPC as the number of inclusions was 514 significantly higher during the initial days of culture, but decreased substantially when rMAPC were 515 maintained in culture which correlated with a restoration of the proliferation rate. One should also note 
516 that higher concentrations of Sinerem ${ }^{\circledR}$ and Endorem ${ }^{\circledR}$ were neccessary for cell labeling to achieve a

517 similar MRI detectability . Although the ploidy of cells was evaluated, and no effect of cell labeling

518 was found, more detailed genotoxicity studies still need to be performed. As no spectral karyotyping 519 or comparative genomic hybridization was performed, we cannot fully ascertain that labeling with 520 (U)SPIO was not genotoxic. As TEM demonstrated that the (U)SPIOs are located nearly exclusively 521 in the cell cytoplasm, genotoxicity is however unlikely.

522 Finally, we evaluated for rMAPC whether cells labeled with Resovist ${ }^{\circledR}$, that was taken up the best in 523 rMAPC and provided the most sensitive labeling in phantoms in vitro, can also be monitored by MRI 524 following transplantation in vivo. When grafted in either mouse or rat brain, with or without stroke, labeled rMAPC were visualized until 15 days after transplantation. In the absence of brain injury, no clear migration of the particles was observed. When grafted in animals that previously underwent photothrombotic stroke, some migration of cells was seen. However, whether this was spontaneous 528 migration along the less dense brain tissue in the Corpus Callosum or directed migration towards the 529 stroke region is still being examined. That the labeled rMAPC did not migrate into the lesion, may be 530 due to the creation of scar tissue around the photothrombotic ischemic lesion (3). As unlabeled cells 531 showed the same pattern, these studies demonstrate that cell labeling does not affect the ability of stem / progenitor cells to migrate in vivo.

533 In conclusion, our study highlights that it is necessary to evaluate the efficiency of cell labeling for 534 every new cell-contrast agent combination whose fate is being followed in vivo. Secondly, the effect 535 on biological behavior of cells should be examined. We here found an effect of labeling on the cell 536 proliferation, but not differentiation, consistent with the fact that other investigators have demonstrated 537 for instance also effects of labeling on the in vivo distribution of MSC $(34,37)$.

538 Although labeling of stem cells with MRI is promising, there are some limitations. First, more optimal 539 particles are needed, that can be taken up by cells without need for potentially toxic transfection agents 540 such as magnetoliposomes (44). A second problem is the dilution of the particle over time when cells 541 divide. If the grafted cells continue to proliferate, this will lead to loss of signal in the majority of the 
542 graft. This problem is not seen in animal models with BLI, as labeling is due to stable transduction of

543 a plasmid or vector in cells (49).

544

545

546

547

548 


\section{Acknowledgments}

550 We would like to thank Tine Decuyper ${ }^{\mathrm{a}}$, Nathalie Feyaerts ${ }^{\mathrm{a}}$, Sarah Mertens ${ }^{\mathrm{a}}$ and Manja Muijtjens ${ }^{\mathrm{a}}$ for 551 excellent technical assistance with cell cultures, cytogenetics and RT-qPCR.

552 We are thankful to Guerbet, Roissy, France for the generous gift of Sinerem ${ }^{\circledR}$ and Endorem ${ }^{\circledR}$.

553 Annelies Crabbe is a research assistant of the Flemish Fund for Scientific Research (FWO 554 Vlaanderen). Caroline Vandeputte is funded by a grant from the Institute for the Promotion of 555 Innovation through Science and Technology in Flanders (IWT Vlaanderen). Angel Ayuso Sacido is 556 supported by RETICS.

557 We gratefully acknowledge the financial support by the European Commission for EC-FP6 network 558 DiMI (LSHB-CT-2005-512146), EC-FP6-STREP-STROKEMAP, EC-FP7 network ENCITE (2008559 201842), IWT (IWT-60838-BRAINSTIM), and the K.U. Leuven Centers of Excellence 'MoSAIC' 560 and 'SCIL'.

561 We thank Aneta Schaap-Oziemlak for her critical review of the manuscript.

562

563

564

565

566 
571 1.Arbab, A. S.; Yocum, G. T.; Rad, A. M.; Khakoo, A. Y.; Fellowes, V.; Read, E. J.; Frank, J. A. 572 Labeling of cells with ferumoxides-protamine sulfate complexes does not inhibit function or 573 differentiation capacity of hematopoietic or mesenchymal stem cells. NMR Biomed. 18(8):553-559; 5742005.

575 2. Arbab, A. S.; Yocum, G. T.; Wilson, L. B.; Parwana, A.; Jordan, E. K.; Kalish, H.; Frank, J. A. 576 Comparison of transfection agents in forming complexes with ferumoxides, cell labeling efficiency, 577 and cellular viability. Mol. Imaging 3(1):24-32; 2004.

578 3. Beck, H.; Semisch, M.; Culmsee, C.; Plesnila, N.; Hatzopoulos, A. K. Egr-1 regulates expression of 579 the glial scar component phosphacan in astrocytes after experimental stroke. Am. J. Pathol. 173(1):77$580 \quad 92 ; 2008$.

581 4. Berger, C.; Rausch M.; Schmidt, P.; Rudin, M. Feasibility and limits of magnetically labeling 582 primary cultured rat $\mathrm{T}$ cells with ferumoxides coupled with commonly used transfection agents. Mol. 583 Imaging 5(2):93-104; 2006.

584 5. Breyer, A.; Estharabadi, N.; Oki, M.; Ulloa, F.; Nelson-Holte, M.; Lien, L.; Jiang, Y. Multipotent 585 adult progenitor cell isolation and culture procedures. Exp. Hematol. 34(11):1596-1601; 2006.

586 6. Bulte, J. W.; Douglas, T.; Witwer, B.; Zhang, S. C.; Strable, E.; Lewis, B. K.; Zywicke, H.; Miller, 587 B.; van Gelderen, P.; Moskowitz, B. M.; Duncan, I. D.; Frank, J. A. Magnetodendrimers allow 588 endosomal magnetic labeling and in vivo tracking of stem cells. Nat. Biotechnol. 19(12):1141-1147; 5892001.

590 7. Bulte, J. W.; Kraitchman, D.L. Iron oxide MR contrast agents for molecular and cellular imaging. $591 \quad$ NMR Biomed. 17(7):484-499; 2004.

592 8. Chen, Y.; Dong, X. J.; Zhang, G. R.; Shao, J. Z.; Xiang, L. X. In vitro differentiation of mouse bone 593 marrow stromal stem cells into hepatocytes induced by conditioned culture medium of hepatocytes. J. 594 Cell. Biochem. 102(1):52-63; 2007.

595 9. Chiao, E.; Elazar, M.; Xing, Y.; Xiong, A.; Kmet, M.; Millan, M. T.; Glenn, J. S.; Wong, W. H.; 596 Baker, J. Isolation and transcriptional profiling of purified hepatic cells derived from human 597 embryonic stem cells. Stem Cells 26(8):2032-2041; 2008. 
10. Conti, L.; Pollard, S. M.; Gorba, T.; Reitano, E.; Toselli, M.; Biella, G.; Sun, Y.; Sanzone, S.;

599 Ying, Q. L.; Cattaneo, E.; Smith, A. Niche-independent symmetrical self-renewal of a mammalian 600 tissue stem cell. PLoS Biol. 3(9):e283; 2005.

601 11. Corot, C.; Robert, P.; Idee, J. M.; Port, M. Recent advances in iron oxide nanocrystal technology 602 for medical imaging. Adv. Drug Deliv. Rev. 58(14):1471-1504; 2006.

603 12. Crich, S. G.; Biancone, L.; Cantaluppi, V.; Duo, D.; Esposito, G.; Russo, S.; Camussi, G.; Aime,

604 S. Improved route for the visualization of stem cells labeled with a Gd-/Eu-chelate as dual (MRI and 605 fluorescence) agent. Magn. Reson. Med. 51(5):938-944; 2004.

606 13. De Bari, C.; Dell'Accio, F.; Tylzanowski, P.; Luyten, F. P. Multipotent mesenchymal stem cells 607 from adult human synovial membrane. Arthritis Rheum. 44(8):1928-1942; 2001.

608 14. De Bari, C.; Dell'Accio, F.; Vanlauwe, J.; Eyckmans, J.; Khan, I. M.; Archer, C. W.; Jones, E. A.; 609 McGonagle, D.; Mitsiadis, T. A.; Pitzalis, C.; Luyten, F. P. Mesenchymal multipotency of adult 610 human periosteal cells demonstrated by single-cell lineage analysis. Arthritis Rheum. 54(4):1209$611 \quad 1221 ; 2006$.

612 15. Guillot, P. V.; De Bari, C.; Dell'accio, F.; Kurata, H.; Polak, J.; Fisk, N. M. Comparative 613 osteogenic transcription profiling of various fetal and adult mesenchymal stem cell sources. 614 Differentiation 76(9):946-957; 2008.

615 16. Himmelreich, U.; Dresselaers, T. Cell labeling and tracking for experimental models using 616 Magnetic Resonance Imaging. Methods 48(2):112-124; 2009.

617 17. Himmelreich, U.; Hoehn M. Stem cell labeling for magnetic resonance imaging. Minim. Invasive 618 Ther. Allied Technol. 17(2):132-142;2008.

619 18. Hoehn, M.; Kustermann, E.; Blunk, J.; Wiedermann, D.; Trapp, T.; Wecker, S.; Focking, M.; 620 Arnold, H.; Hescheler, J.; Fleischmann, B. K.; Schwindt, W.; Buhrle, C. Monitoring of implanted stem 621 cell migration in vivo: a highly resolved in vivo magnetic resonance imaging investigation of experimental stroke in rat. Proc. Natl. Acad. Sci. USA 99(25):16267-16272; 2002.

623 19. Izadpanah, R.; Kaushal, D.; Kriedt, C.; Tsien, F.; Patel, B.; Dufour, J.; Bunnell, B. A. Long-term 624 in vitro expansion alters the biology of adult mesenchymal stem cells. Cancer Res. 68(11):4229-4238; $625 \quad 2008$. 
20. Kilic, N.; Oliveira-Ferrer, L.; Neshat-Vahid, S.; Irmak, S.; Obst-Pernberg, K.; Wurmbach, J. H.;

627 Loges, S.; Kilic, E.; Weil, J.; Lauke, H.; Tilki, D.; Singer, B. B.; Ergun, S. Lymphatic reprogramming 628 of microvascular endothelial cells by CEA-related cell adhesion molecule-1 via interaction with 629 VEGFR-3 and Prox1. Blood 110(13):4223-4233; 2007.

630 21. Kim, J.; Chu, J.; Shen, X.; Wang, J.; Orkin, S. H. An extended transcriptional network for 631 pluripotency of embryonic stem cells. Cell 132(6):1049-1061; 2009.

632 22. Koenig, S.; Krause, P.; Hosseini, A. S.; Dullin, C.; Rave-Fraenk, M.; Kimmina, S.; Entwistle, A. 633 L.; Hermann, R. M.; Hess, C. F.; Becker, H.; Christiansen, H. Noninvasive imaging of liver 634 repopulation following hepatocyte transplantation. Cell Transplant. 18(1):69-78; 2009.

635 23. Kostura, L.; Kraitchman, D. L.; Mackay, A. M.; Pittenger, M. F.; Bulte, J. W. Feridex labeling of 636 mesenchymal stem cells inhibits chondrogenesis but not adipogenesis or osteogenesis. NMR Biomed. $637 \quad 17(7): 513-517 ; 2004$.

638 24. Kustermann, E.; Himmelreich, U.; Kandal, K.; Geelen, T.; Ketkar, A.; Wiedermann, D.; Strecker, 639 C.; Esser, J.; Arnhold, S.; Hoehn, M. Efficient stem cell labeling for MRI studies. Contrast Media 640 Mol. Imaging 3(1):27-37; 2008.

641 25. Kuznetsov, S. A.; Mankani, M. H.; Robey, P. G. Effect of serum on human bone marrow stromal 642 cells: ex vivo expansion and in vivo bone formation. Transplantation 70(12):1780-1787; 2000.

643 26. Liu, F.; Akiyama, Y.; Tai, S.; Maruyama, K.; Kawaguchi, Y.; Muramatsu, K.; Yamaguchi, K. 644 Changes in the expression of CD106, osteogenic genes, and transcription factors involved in the 645 osteogenic differentiation of human bone marrow mesenchymal stem cells. J. Bone Miner. Metab. 646 26(4): 312-320; 2008.

647 27. Lopez-Gonzalez, R.; Kunckles, P.; Velasco, I. Transient Recovery in a Rat Model of Familial 648 Amyotrophic Lateral Sclerosis after Transplantation of Motor Neurons Derived From Mouse 649 Embryonic Stem Cells. Cell Transplant. 18(10-11):1171-1181; 2009.

650 28. Mai, X. L.; Ma, Z. L.; Sun, J. H.; Ju, S. H.; Ma, M.; Teng, G. J. Assessments of proliferation 651 capacity and viability of New Zealand rabbit peripheral blood endothelial progenitor cells labeled with 652 superparamagnetic particles. Cell Transplant. 18(2):171-181; 2009. 
29. Modo, M.; Cash, D.; Mellodew, K.; Williams, S. C.; Fraser, S. E.; Meade, T. J.; Price, J.; Hodges, H. Tracking transplanted stem cell migration using bifunctional, contrast agent-enhanced, magnetic resonance imaging. Neuroimage 17(2):803-811; 2002.

30. Modo, M.; Hoehn, M.; Bulte, J. W. Cellular MR imaging. Mol. Imaging 4(3):143-164; 2005.

31. Neri, M.; Maderna, C.; Cavazzin, C.; Deidda-Vigoriti, V.; Politi, L. S.; Scotti, G.; Marzola, P.; Sbarbati, A.; Vescovi, A. L.; Gritti, A. Efficient in vitro labeling of human neural precursor cells with superparamagnetic iron oxide particles: relevance for in vivo cell tracking. Stem Cells 26(2):505-516; 2008.

32. Niwa, H.; Miyazaki, J.; Smith, A. G. Quantitative expression of Oct-3/4 defines differentiation, dedifferentiation or self-renewal of ES cells. Nat. Genet. 24(4):372-376; 2000.

33. Peister, A.; Mellad, J. A.; Larson, B. L.; Hall, B. M.; Gibson, L. F.; Prockop, D. J. Adult stem cells from bone marrow (MSCs) isolated from different strains of inbred mice vary in surface epitopes, rates of proliferation, and differentiation potential. Blood 103(5):1662-1668; 2004.

\section{Pisanic, T. R., II.; Blackwell, J. D.; Shubayev, V. I.; Finones, R. R.; Jin, S. Nanotoxicity of iron} oxide nanoparticle internalization in growing neurons. Biomaterials 28:2572-2581; 2007.

35. Pittenger, M. F.; Mackay, A. M.; Beck, S. C.; Jaiswal, R. K.; Douglas, R.; Mosca, J. D.; Moorman, M. A.; Simonetti, D. W.; Craig, S.; Marshak, D. R. Multilineage potential of adult human mesenchymal stem cells. Science 284(5411):143-147; 1999.

36. Prockop, D. J. Marrow stromal cells as stem cells for nonhematopoietic tissues. Science 276(5309):71-74; 1997.

37. Schafer, R.; Ayturan, M.; Bantleon, R.; Kehlbach, R.; Siegel, G.; Pintaske, J.; Conrad, S.; Wolburg, H.; Northoff, H.; Wiskirchen, J.; Weissert, R. The use of clinically approved small particles of iron oxide (SPIO) for labeling of mesenchymal stem cells aggravates clinical symptoms in experimental autoimmune encephalomyelitis and influences their in vivo distribution. Cell Transplant. 17(8):923-941; 2008.

38. Schafer, R.; Kehlbach, R.; Muller, M.; Bantleon, R.; Kluba, T.; Ayturan, M.; Siegel, G.; Wolburg, H.; Northoff, H.; Dietz, K.; Claussen, C. D.; Wiskirchen, J. Labeling of human mesenchymal stromal 
cells with superparamagnetic iron oxide leads to a decrease in migration capacity and colony

681 formation ability. Cytotherapy 11(1):68-78; 2009

682 39. Shapiro, E. M.; Gonzalez-Perez, O.; Manuel Garcia-Verdugo, J.; Alvarez-Buylla, A.; Koretsky, A.

683 P. Magnetic resonance imaging of the migration of neuronal precursors generated in the adult rodent 684 brain. Neuroimage 32(3):1150-1157; 2006.

685 40. Sheen, V. L; Macklis, J. D. Targeted neocortical cell death in adult mice guides migration and 686 differentiation of transplanted embryonic neurons. J. Neurosci. 15(12):8378-8392; 1995.

687 41. Shihabuddin, L. S.; Hertz, J. A.; Holets, V. R.; Whittemore, S. R. The adult CNS retains the 688 potential to direct region-specific differentiation of a transplanted neuronal precursor cell line. J. 689 Neurosci. 15(10):6666-6678; 1995.

690 42. Siglienti, I.; Bendszus, M.; Kleinschnitz, C.; Stoll, G. Cytokine profile of iron-laden macrophages: 691 implications for cellular magnetic resonance imaging. J. Neuroimmunol. 173(1-2):166-173; 2006.

692 43. Snyder, E. Y.; Deitcher, D. L.; Walsh, C.; Arnold-Aldea, S.; Hartwieg, E. A.; Cepko, C. L. 693 Multipotent neural cell lines can engraft and participate in development of mouse cerebellum. Cell $694 \quad 68(1): 33-51 ; 1992$.

695 44. Soenen, S. J.; Baert, J.; De Cuyper, M. Optimal conditions for labelling of 3T3 fibroblasts with 696 magnetoliposomes without affecting cellular viability. Chembiochem. 8(17):2067-2077; 2007.

697 45. Stroh, A.; Zimmer, C.; Gutzeit, C.; Jakstadt, M.; Marschinke, F.; Jung, T.; Pilgrimm, H.; Grune, T. 698 Iron oxide particles for molecular magnetic resonance imaging cause transient oxidative stress in rat 699 macrophages. Free Radic. Biol. Med. 36(8):976-984; 2004.

700 46. Sumner, J. P.; Shapiro, E. M.; Maric, D.; Conroy, R.; Koretsky, A. P. In vivo labeling of adult 701 neural progenitors for MRI with micron sized particles of iron oxide: quantification of labeled cell 702 phenotype. Neuroimage 44(3):671-678; 2009.

703 47. Torrente, Y.; Polli E. Mesenchymal stem cell transplantation for neurodegenerative diseases. Cell 704 Transplant. 17(10-11):1103-1113; 2008.

705 48. Ulloa-Montoya, F.; Kidder, B. L.; Pauwelyn, K. A.; Chase, L. G.; Luttun, A.; Crabbe, A.; 706 Geraerts, M.; Sharov, A. A.; Piao, Y.; Ko, M. S.; Hu, W. S.; Verfaillie, C. M. Comparative 
transcriptome analysis of embryonic and adult stem cells with extended and limited differentiation

708 capacity. Genome Biol. 8(8):R163; 2007.

709 49. Waerzeggers, Y.; Klein, M.; Miletic, H.; Himmelreich, U.; Li, H.; Monfared, P.; Herrlinger, U.;

710 Hoehn, M.; Coenen, H. H.; Weller, M.; Winkeler, A.; Jacobs, A. H. Multimodal imaging of neural

711 progenitor cell fate in rodents. Mol. Imaging 7(2):77-91; 2008.

712 50. Wen, J.; Hu, Q.; Li, M.; Wang, S.; Zhang, L.; Chen, Y.; Li, L. Pax6 directly modulate Sox2

713 expression in the neural progenitor cells. Neuroreport 19(4):413-417; 2008.

714 51. Wideroe, M.; Olsen, O.; Pedersen, T. B.; Goa, P. E.; Kavelaars, A.; Heijnen, C.; Skranes, J.;

715 Brubakk, A. M.; Brekken, C. Manganese-enhanced magnetic resonance imaging of hypoxic-ischemic

716 brain injury in the neonatal rat. Neuroimage 45(3):880-890; 2009.

717 52. Yamada, M; Yang P. In vitro labeling of human embryonic stem cells for magnetic resonance 718 imaging. J. Vis. Exp. 17:827; 2008.

719 53. Yamashita, T.; Deguchi, K.; Nagotani, S.; Kamiya, T.; Abe, K. Gene and stem cell therapy in 720 ischemic stroke. Cell Transplant. 18(9):999-1002; 2009.

721 54. Yeh, T. C.; Zhang, W.; Ildstad, S. T.; Ho, C. In vivo dynamic MRI tracking of rat T-cells labeled 722 with superparamagnetic iron-oxide particles. Magn. Reson. Med. 33(2):200-208; 1995.

723

724

725

726

727

728

729

730 
732 Table1: Statistical analysis of number, size and density of inclusions in rMAPC. Cells were fixed 733 and evaluated under TEM; $\mathrm{N}$ = number of samples. Density was measured by visual quantification 734 giving number 0 (as control for unlabeled cells) till 5 (big inclusions). Data are presented as mean $\pm \mathrm{St}$ 735 error; $(*) \mathrm{p}<0.05$.

\begin{tabular}{llll}
\hline & Resovist $^{\circledR}$ & Endorem $^{\circledR}$ & Sinerem $^{\circledR}$ \\
\hline Number of inclusions & $2.93^{*} \pm 0.53(\mathrm{n}=14)$ & $3.36^{*} \pm 0.84(\mathrm{n}=17)$ & $6.35 \pm 0.86(\mathrm{n}=20)$ \\
\hline Size of inclusions ( $\boldsymbol{\mu m})$ & $1.74^{*} \pm 0.23(\mathrm{n}=40)$ & $1.20 \pm 0.07(\mathrm{n}=57)$ & $1.46^{*} \pm 0.05(\mathrm{n}=127)$ \\
\hline Density of inclusions & $2.36^{*} \pm 0.21(\mathrm{n}=40)$ & $2.56^{*} \pm 0.16(\mathrm{n}=57)$ & $1.05 \pm 0.02(\mathrm{n}=127)$ \\
\hline
\end{tabular}

736

737

738

739

740

741

742

743

744

745

746 
Figure 1: Determination of iron content in rMAPC, mESC and mMSC. (A-C) Iron quantification was performed by ICP-MS. Stem cells were cultured for $24 \mathrm{hrs}$ with Resovist ${ }^{\circledR}$, Endorem ${ }^{\circledR}$ or Sinerem $^{\circledR}$, washed with PBS twice and cultured for 1, 2 or 3 days without (U)SPIOs before iron quantification. (A) rMAPC, (B) mESC, (C) mMSC (n=3); $<<0.016(*)$. (D-F) Number of endosomal inclusions over time determined by TEM. mMSC, rMAPC and mESC were labeled with Resovist ${ }^{\circledR}$. The amount of inclusions per cell type was measured at time points day 1 , day 3 and day 5 after labeling $754(\mathrm{n}=5)$.

755

Figure 2: In vitro visualization of cells by MRI. Agar phantoms were filled with 250, 75, 15 and 5 rMAPC, mMSC and mESC per microliter, following labeling of the cells with Endorem ${ }^{\circledR}$, Resovist ${ }^{\circledR}$ or Sinerem ${ }^{\circledR}$. (A) 3D T2*-weighted gradient-echo MRI of phantoms loaded with cells labeled for $24 \mathrm{hrs}$, followed by $24 \mathrm{hrs}$ culture in (U)SPIO free medium. The presence of contrast agent is illustrated by hypointense (dark) contrast. (B) T2-map (left) and T2*-weighted MRI (right) of Endorem ${ }^{\circledR}$ labeled mESC. The phantom was loaded with labeled cells at concentration of 75 cells $/ \mu 1$ cultured for an additional (1) $1 \mathrm{hr}$, (2) $24 \mathrm{hrs,} \mathrm{(3)} 48 \mathrm{hrs,} \mathrm{(4)} 72 \mathrm{hrs}$ and (5) $120 \mathrm{hrs}$ in Endorem ${ }^{\circledR}$-free medium.

Figure 3: Population doubling time of rMAPC, mESC and mMSC labeled with different (U)SPIOs. Population doubling time (PDT $=\mathrm{T} \times \mathrm{Ln} 2 / \mathrm{Ln}(\mathrm{A} / \mathrm{A} 0)$, with $\mathrm{T}=$ time between two cell counts, $\mathrm{A}=$ the number of cells at end, $\mathrm{A} 0=$ the initial number of cells) of cells calculated from day 0 till day 7 after (U)SPIO labeling for the following conditions: control, Resovist ${ }^{\circledR}$, Sinerem ${ }^{\circledR}$, Endorem $^{\circledR}$. (A) mMSC, (B) mESC and (C) $\operatorname{rMAPC}(n=3) ; p=<0.016(*)$.

Figure 4: Comparison of phenotype of labeled and unlabeled stem cells. mMSC, rMAPC, and mESC were labeled with Endorem $^{\circledR}$, Resovist ${ }^{\circledR}$, or Sinerem ${ }^{\circledR}$. (A-B) Two days after culture in (U)SPIO-free medium, RNA was extracted from rMAPC and mESC and levels of Oct-4 transcripts were determined by RT-qPCR. Data are shown as Delta $\mathrm{Ct}(\mathrm{n}=3)$ compared with the house keeping gene Gapdh for (A) mESC and (B) rMAPC. (C-D) Three days after culture in (U)SPIO-free medium, the phenotype of mMSC and rMAPC was evaluated by FACS of cells labeled with antibodies against 
CD44 and c-kit (mMSC) and CD44 and CD31 (rMAPC) Isotype controls are shown in frame. FACS analysis plot for 1 of 3 representative experiment (C) mMSC; (D) rMAPC.

Figure 5: Differentiation capacity of mMSC and rMAPC labeled with (U)SPIOs in comparison to unlabeled cells. (A-C) mMSC labeled with Endorem ${ }^{\circledR}$, Resovist ${ }^{\circledR}$, or Sinerem ${ }^{\circledR}$ were allowed to differentiate towards osteoblasts (A-B) or adipocytes (C). (A) Osteoblast differentiation was induced using osteogenic medium and progeny of labeled and unlabeled cells evaluated by immunohistochemistry for alkaline phosphatase staining at day 6 , and calcium measurement at day 14 (n=2). (B) Specific transcripts measured by RT-qPCR. Delta Ct-values of Bsp and Alp are shown. $\mathrm{p}=<0.05\left(^{*}\right)(\mathrm{C})$ To induce adipogenic differentiation, labeled and unlabeled cells were cultured with insulin, and progeny evaluated on day 21 by Oil Red O staining. Left: control, right: adipogenic stimulation. Fat vacuoles are formed in the cells. (D-F) rMAPC labeled with Endorem ${ }^{\circledR}$, Resovist ${ }^{\circledR}$, or Sinerem ${ }^{\circledR}$ were allowed to differentiate to hepatocyte- (D), endothelium- (E) and neuroprogenitor-like (F) cells as described in materials and methods. Cells were harvested and on day 21, 9 and 6, respectively, and expression of hepatic, endothelial and neuroprogenitor transcripts evaluated by RTqPCR (n=9). Delta Ct values are shown. (G-N) Evaluation of iron inclusions in differentiated rMAPC and mMSC by TEM. rMAPC labeled with Endorem ${ }^{\circledR}$, Resovist $^{\circledR}$, or Sinerem ${ }^{\circledR}$, were differentiated towards hepatocyte-like, endothelium-like and neuroprogenitor-like cells. On day 21, 9 and 6 respectively, cells were evaluated for presence of iron inclusion using TEM. Labeled mMSC were differentiated towards osteoblasts. On day 14 cells were evaluated for presence of iron inclusions using TEM. (G) rMAPC liver Resovist ${ }^{\circledR}$, (H) rMAPC liver Endorem ${ }^{\circledR}$, (I) rMAPC endothelium Resovist $^{\circledR}$, (J) rMAPC Endothelium Endorem ${ }^{\circledR}$, (K) rMAPC endothelium Sinerem ${ }^{\circledR}$, (L) mMSC osteoblast Endorem $^{\circledR}$, (M) mMSC osteoblast Resovist ${ }^{\circledR},(\mathrm{N}) \mathrm{mMSC}$ osteoblast Sinerem ${ }^{\circledR}$. Iron particles are seen as black cluster or indicated by arrows.

Figure 6: Determination of in vivo detectability by MR imaging. Different concentrations of rMAPC were labeled with Resovist ${ }^{\circledR}$, suspended in $2 \mu 1$ medium and were injected in the striatum of N OD-SCID $\gamma \mathrm{c}^{-/}$mice. 3D T2*-weighted MR images are shown for (A) control animal (coronal and corresponding (dotted lines) axial view with (1) 10,000 labeled MAPC, (2) 10,000 unlabeled MAPC, 
800 (3) saline injection and (4) $2 \mu 1$ medium + Resovist $^{\circledR}$ ) and (B) control animal injected with labeled 801 MAPC (coronal and axial view; (1) left 10,000 cells and (2) right 50,000 cells). (C-D) GFP staining of 802 cells; (C) striatum; (D) Cells engrafting along the Corpus Callosum; CC: Corpus Callosum, Cor: 803 cortex, Str: striatum, ML: midline, SR: stroke region.

804 Figure 7: In vivo tracking of labeled cells in the rat brain. 100,000 cells were injected in the brain 805 of rats with photothrombotic lesions (left hemisphere) in the contralateral hemisphere (left). The 806 panels show left: a diffusion weighted MRI to illustrate the extend of the lesion (acquired immediately 807 after photothrombosis and $24 \mathrm{hrs}$ before cell engraftment); middle: 3D T2*-weighted MRI acquired 24 808 hrs after cell engraftment (coronal view) and on the right the corresponding axial view. The arrows 809 indicate the injection sites. Images were acquired from (A) an animal with engraftment of 100,000 810 Resovist $^{\circledR}$ labeled mMSC (left and right hemisphere; no migration was observed); (B) an animal with 811 engraftment of 100,000 unlabeled rMAPC (left and right); (C) an animal with engraftment of 100,000 812 Resovist $^{\circledR}$ labeled rMAPC (left and right, Note the migration of cells from the injection site towards 813 the site of photothrombotic injury); (D) GFP staining of tissue slices from animal (C), and (E): 814 hematoxylin-eosin staining of tissue slices from animal (C). (D) and (E): CC: Corpus Callosum, SR: 815 Stroke region, Str: Striatum. 
Figure 1:
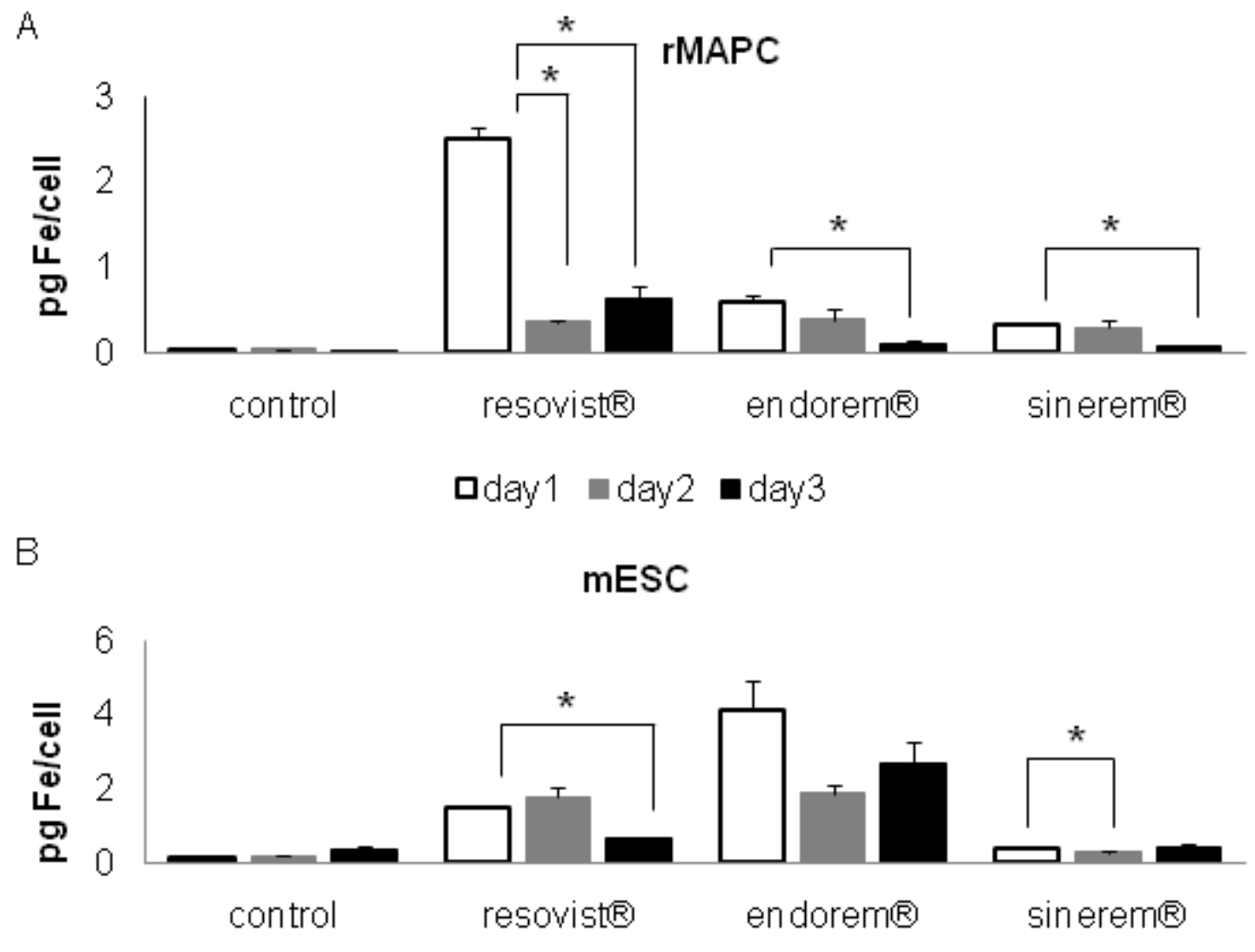

C

口day1 aday2 $\square$ day3

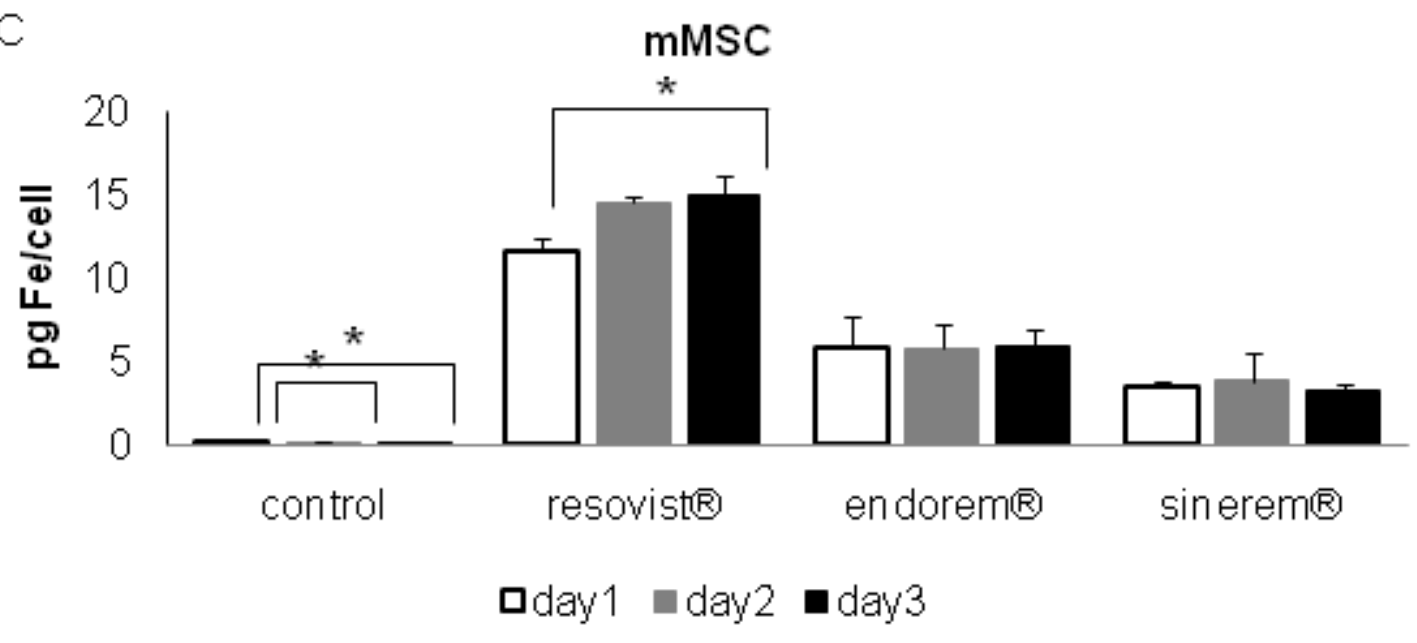



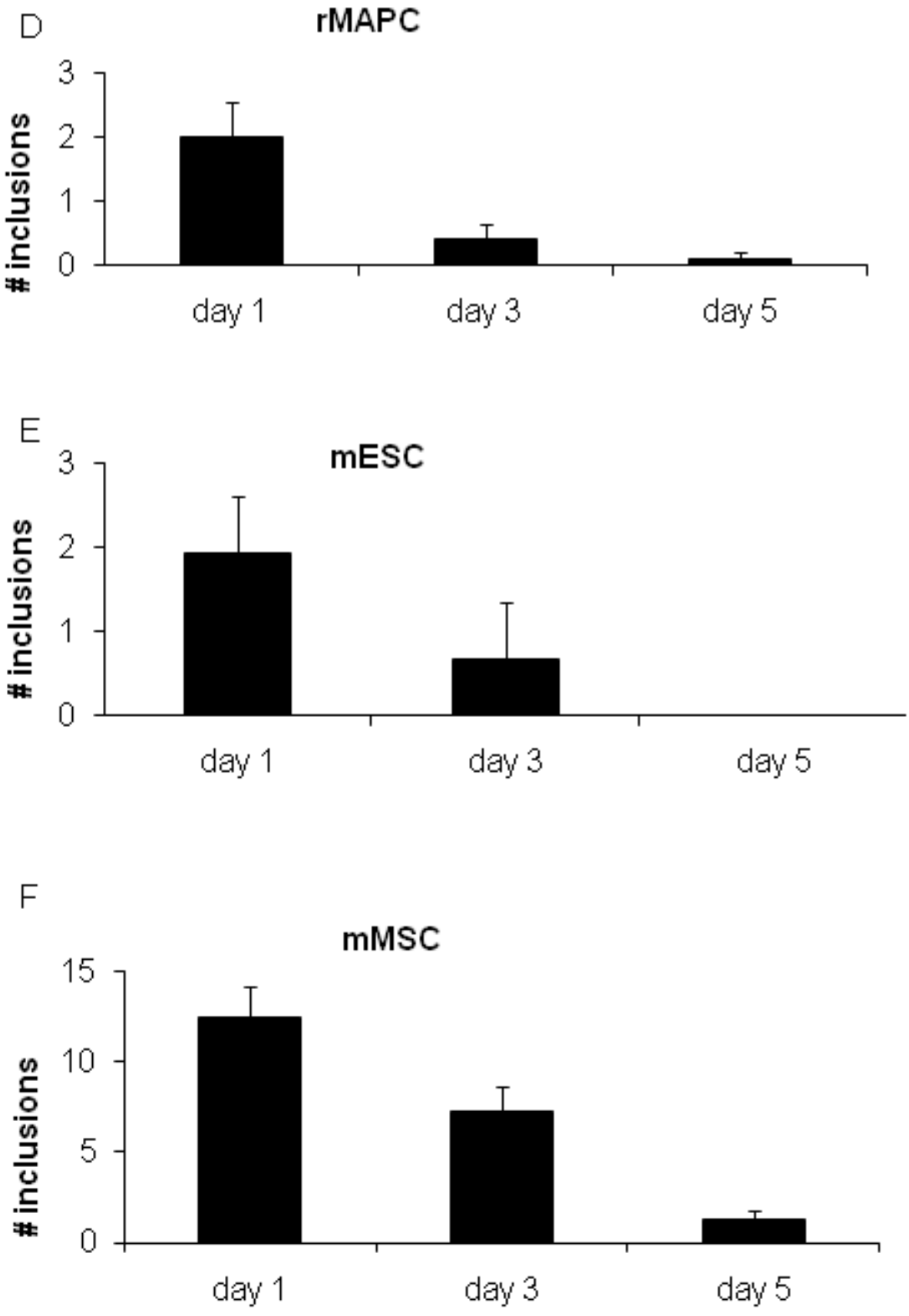
Figure 2:

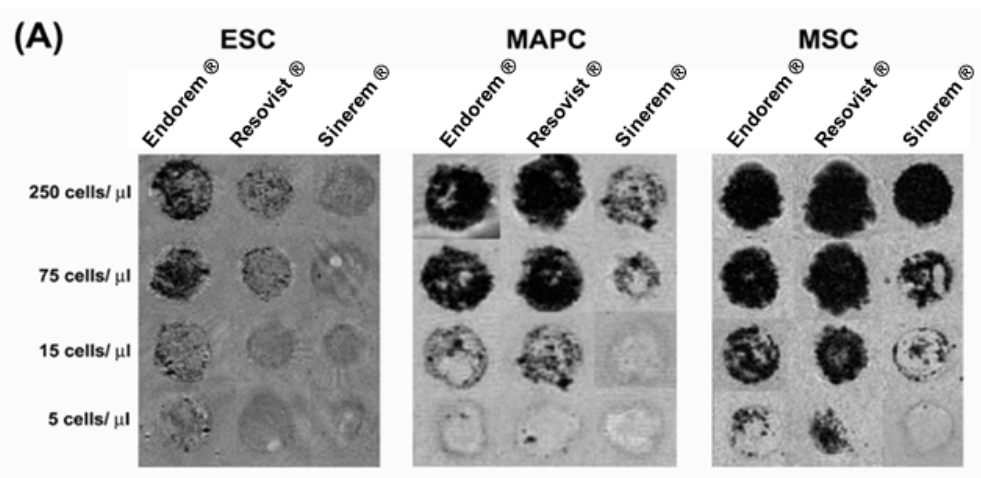

(B)

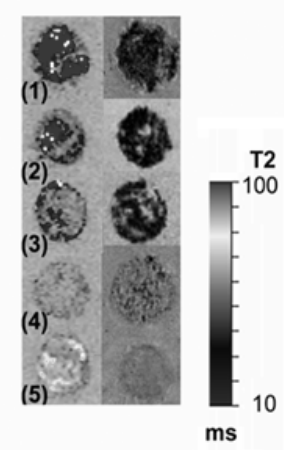


Figure 3:
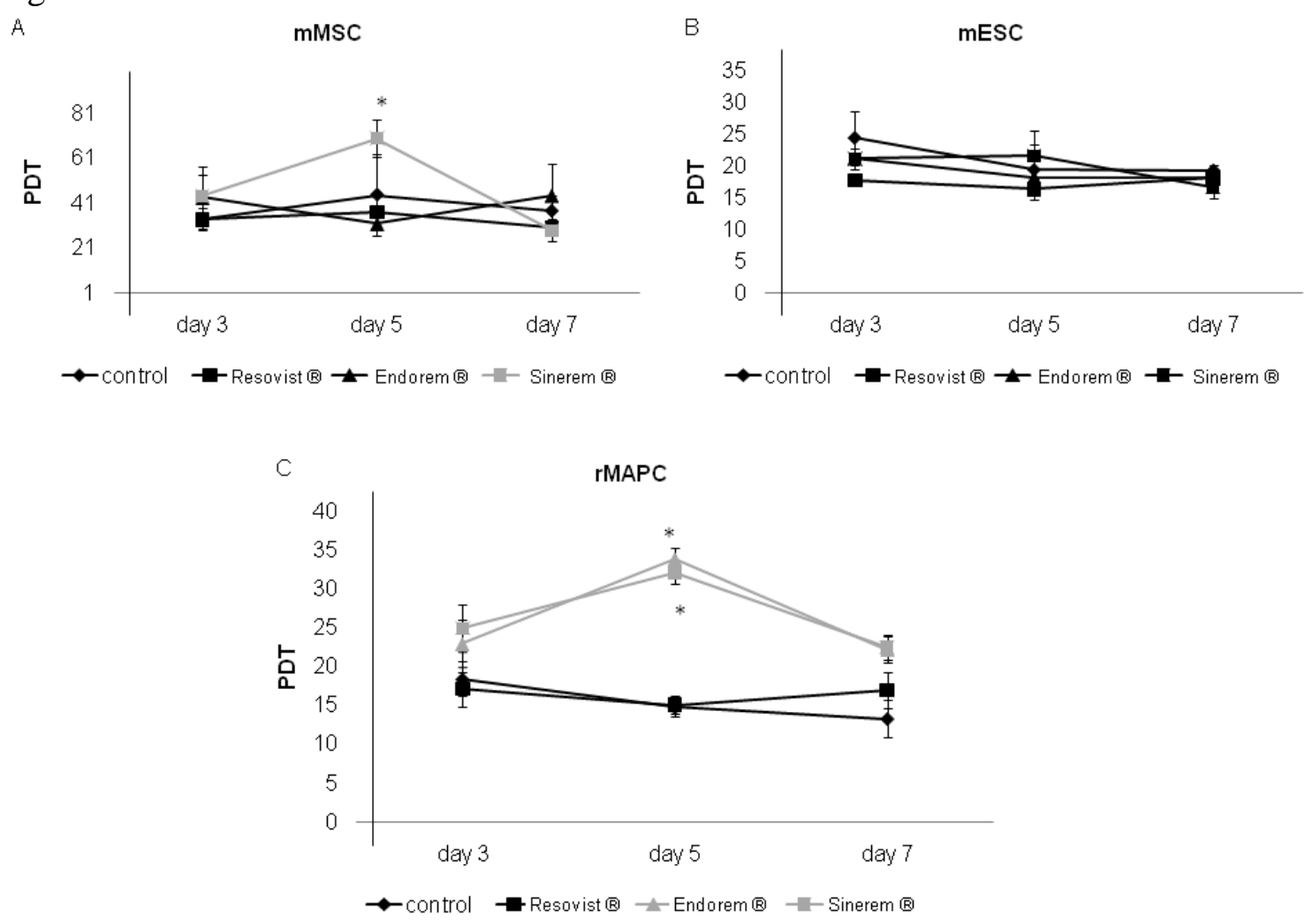
Figure 4:
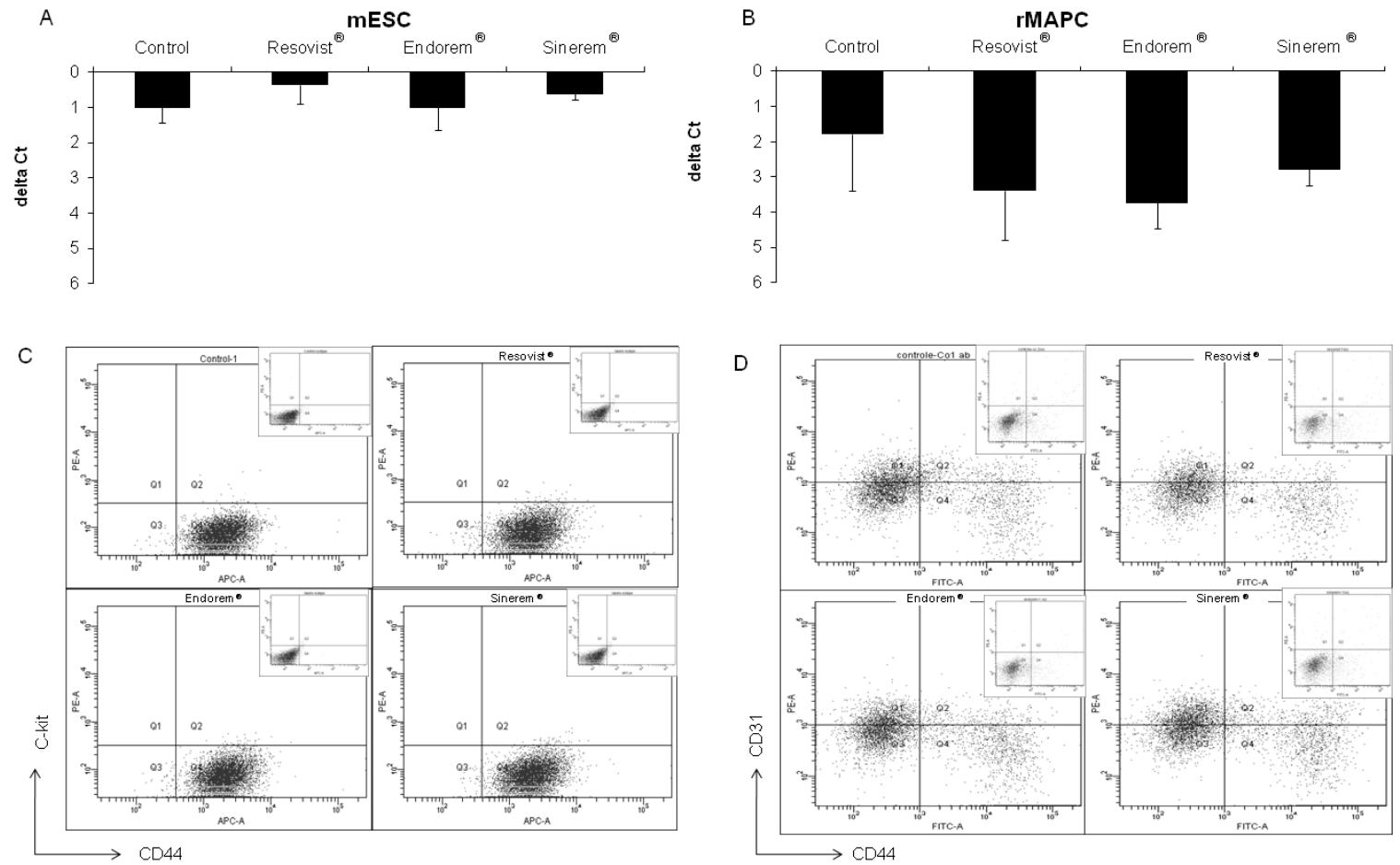
Figure 5:
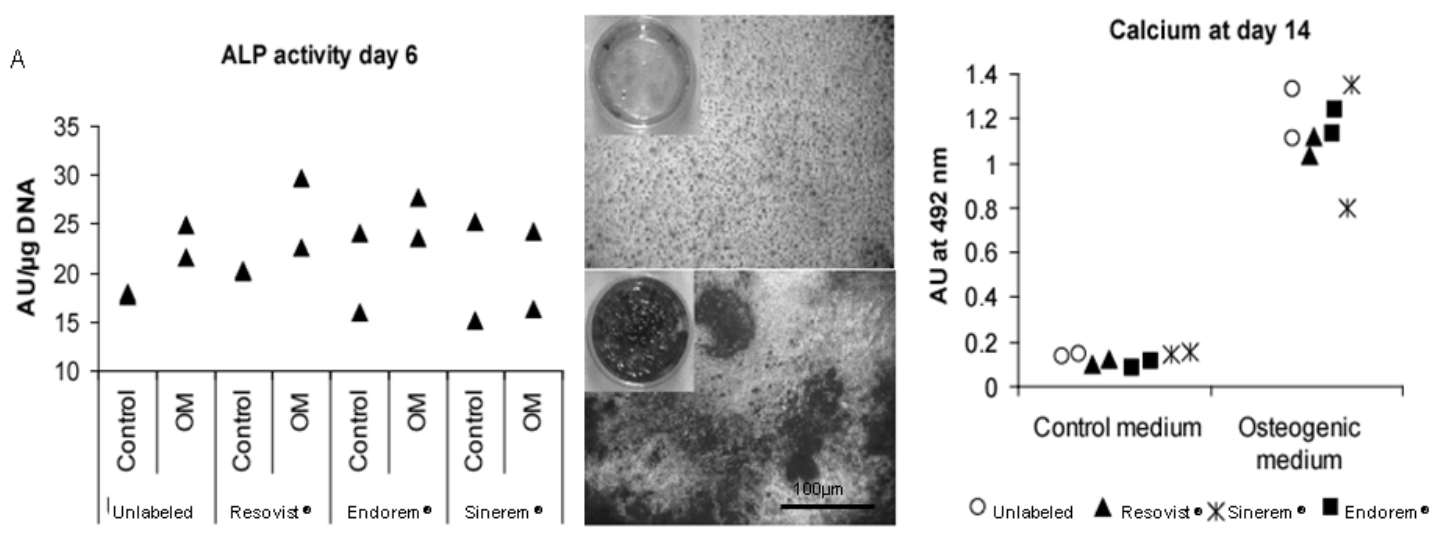

ALP

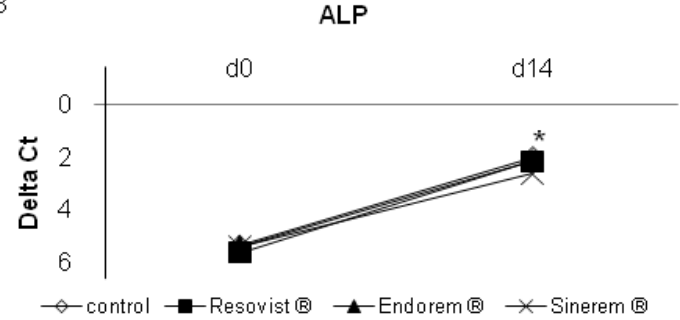

C

$\mathrm{O}_{\text {Unlabeled }} \boldsymbol{\Delta}$ Resovist $\bullet X_{\text {Sinerem }} \bullet \boldsymbol{⿴}_{\text {Endorem }} \bullet$
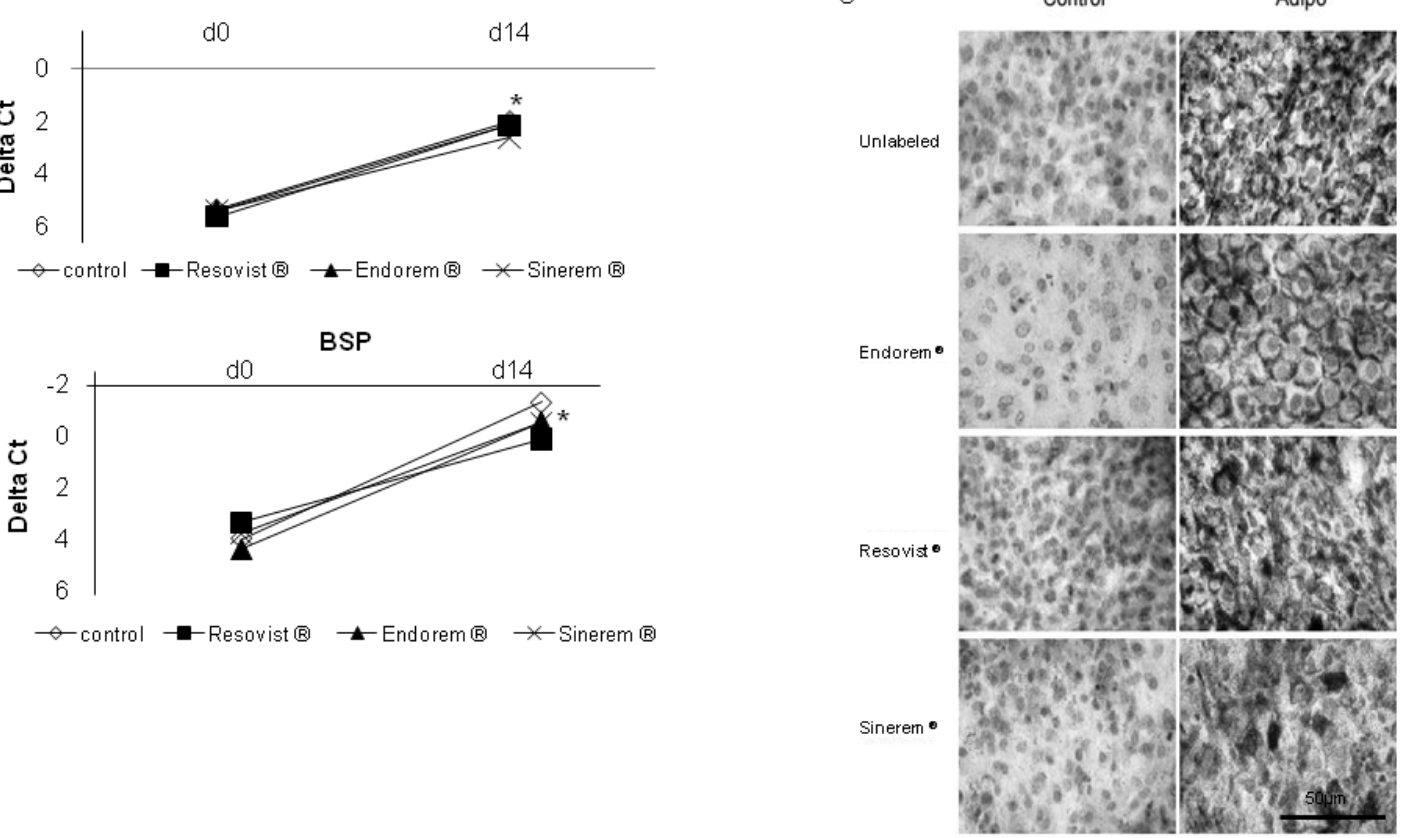

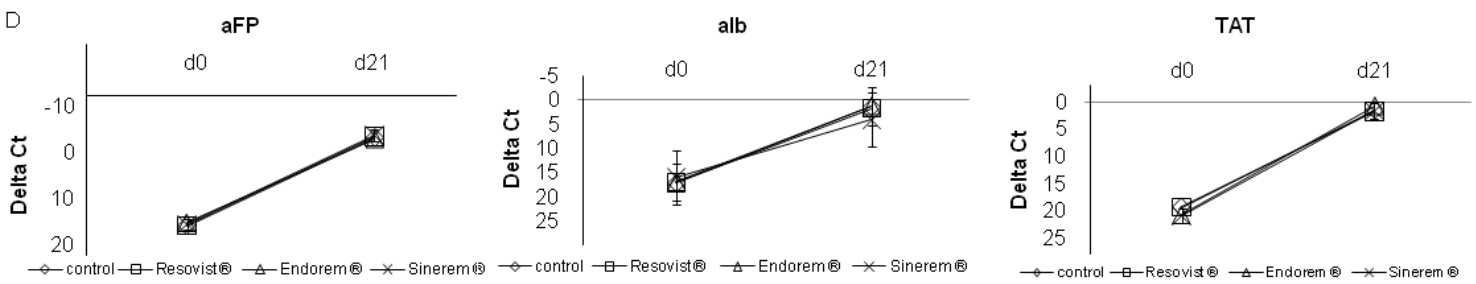

E

Flk1

Prox1
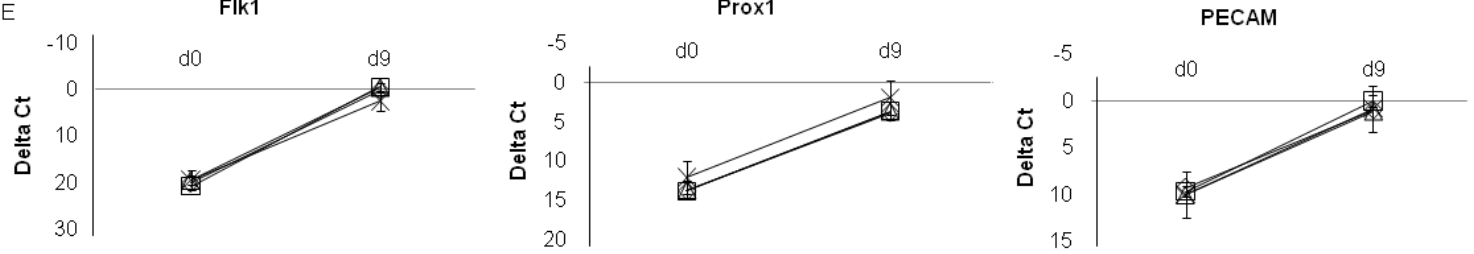

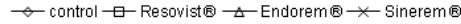

F

Sox2
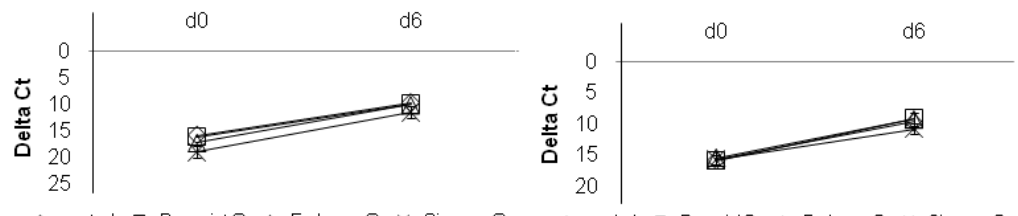

$\longrightarrow$ control $\square$ Resovist $\mathbb{Q} \triangle$ Endorem $\mathbb{R} *$ Sinerem

$\multimap$ control $\rightarrow$ Resovist $\rightarrow$ Endorem $\rightarrow$ Sinerem 
Figure 6:
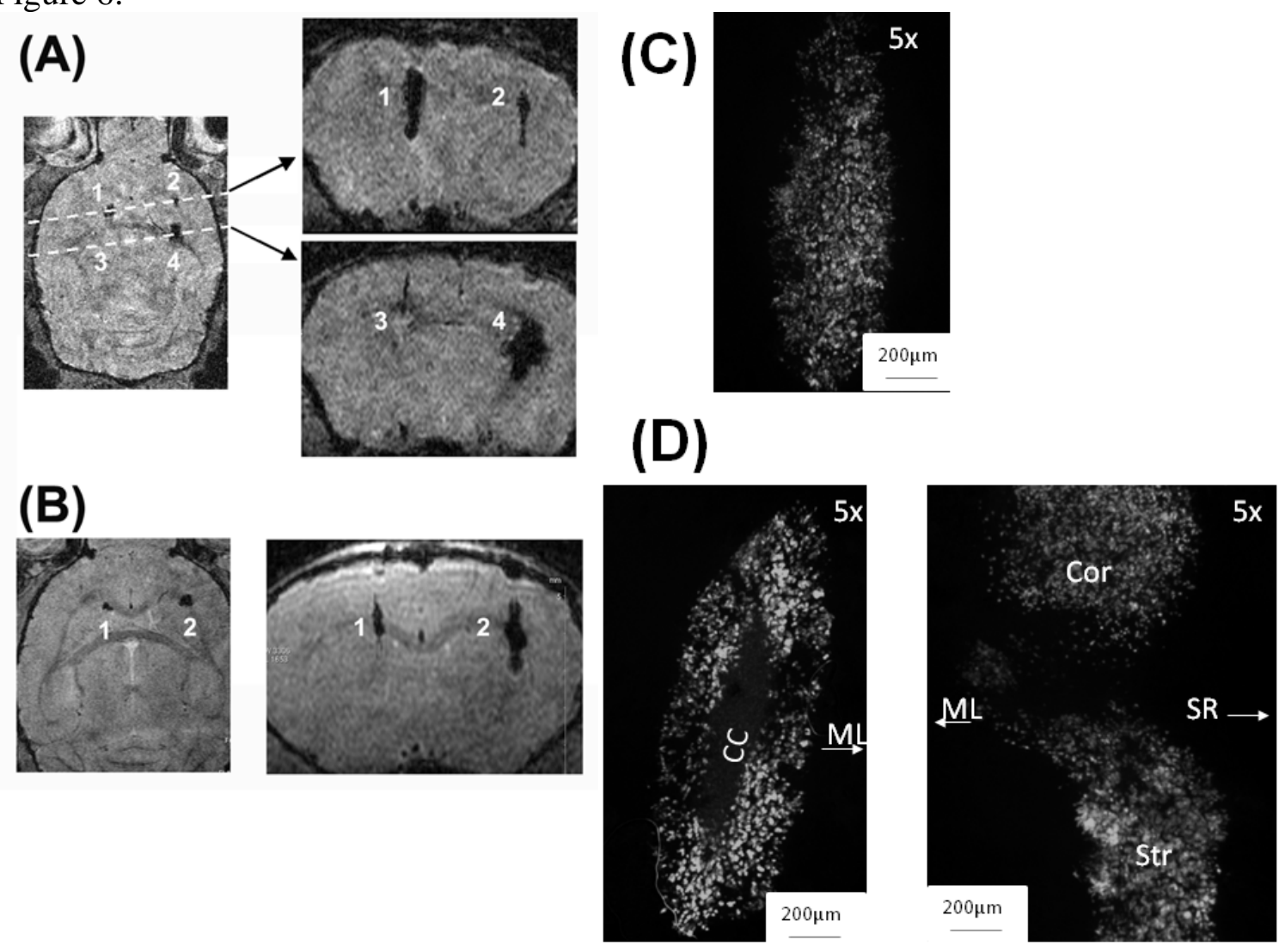
Figure 7:

(A)

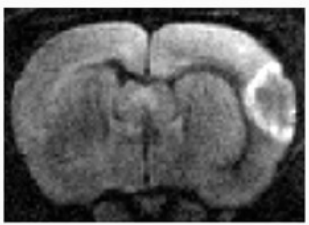

(B)
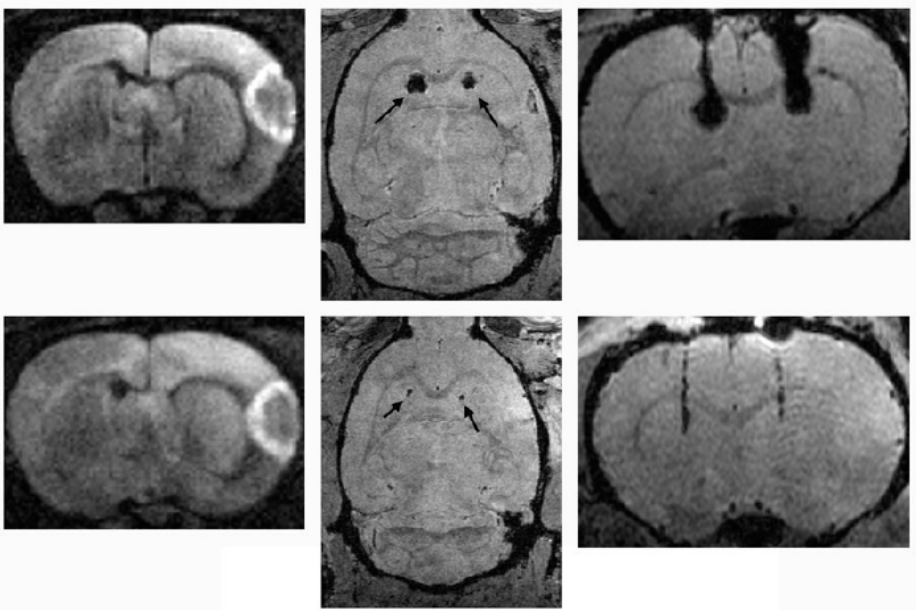

(C)
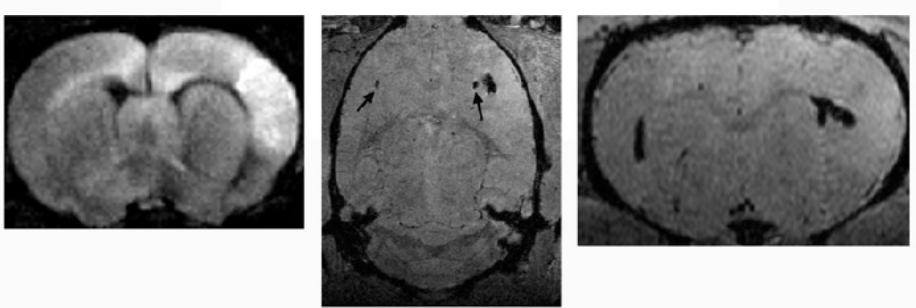

(D)

(E)

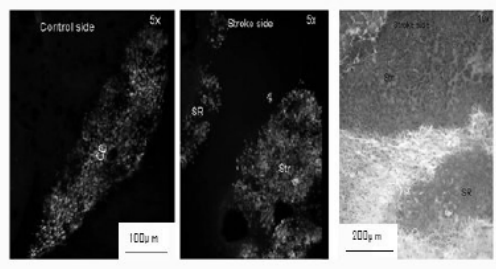

